\title{
The Tetrahymena metallothionein gene family: twenty-one new cDNAs, molecular characterization, phylogenetic study and comparative analysis of the gene expression under different abiotic stressors
}

Patricia de Francisco ${ }^{1}$, Laura María Melgar², Silvia Díaz ${ }^{1}$ Ana Martín-González and Juan Carlos Gutiérrez ${ }^{1 *}$

\begin{abstract}
Background: Ciliate metallothioneins (MTs) are included in family 7 of the MT superfamily. This family has been divided into two main subfamilies: 7a or CdMTs and 7b or CuMTs. All ciliate MTs reported have been isolated from different Tetrahymena species and present unique features with regard to standard MTs. Likewise, an expression analysis has been carried out on some of MT genes under metal stress, corroborating their classification into two subfamilies.

Results: We isolated 21 new cDNAs from different Tetrahymena species to obtain a wider view of the biodiversity of these conserved genes. Structural analysis (cysteine patterns) and an updated phylogenetic study both corroborated the previous classification into two subfamilies. A new CuMT from a Tetrahymena-related species Ichthyophthirius multifiliis was also included in this general analysis. We detected a certain tendency towards the presentation of a CdMT tri-modular structure in Borealis group species with respect to Australis group. We report for the first time a semi-complete paralog duplication of a CdMT gene originating a new CdMT gene isoform in T. malaccensis. An asymmetry of the codon usage for glutamine residues was detected between $\mathrm{Cd}$ - and CuMTs, and the phylogenetic implications are discussed. A comparative gene expression analysis of several MT genes by qRTPCR revealed differential behavior among them under different abiotic stressors in the same Tetrahymena species.

Conclusions: The Tetrahymena metallothionein family represents a quite conserved protein structure group with unique features with respect to standard MTs. Both Cd-and CuMT subfamilies present very defined and differentiated characteristics at several levels: cysteine patterns, modular structure, glutamine codon usage and gene expression under metal stress, among others. Gene duplication through evolution seems to be the major genetic mechanism for creating new MT gene isoforms and increasing their functional diversity.
\end{abstract}

Keywords: Tetrahymena metallothioneins, cDNAs, Structural characterization, Gene duplication, Phylogeny, Gene expression

\footnotetext{
* Correspondence: juancar@bio.ucm.es

'Departamento Microbiología-lll, Facultad de Biología. C/José Antonio

Novais, 12, Universidad Complutense de Madrid (UCM), 28040 Madrid, Spain

Full list of author information is available at the end of the article
} 


\section{Background}

Metallothioneins (MTs) constitute a superfamily of small ubiquitous cytosolic proteins (25-82 aa, 2.5-8.0 KDa) which are able to bind metal cations through their numerous cysteine (Cys) residues (18-23 Cys organized in conserved domains). Several functions have been proposed for these proteins [1], such as protection from toxic metals and oxidative stress [2], essential-metal homeostasis [3] and protection against xenobiotics [4]. Likewise, they have been implicated in protection against neurodegenerative diseases [5], apoptosis and the biology of aging [6], as well as in processes of development and cellular differentiation [7]. This is the reason why these proteins are considered to be multifunctional proteins, involved in many diverse cellular processes.

Since 1957, when the first MT was described [8], more than 20,000 articles have been dedicated to the study of the structure, biochemical or functional features and gene expression analysis of MTs [9]. MTs have been reported in both eukaryotic organisms (protists, yeasts, phylamentous fungi, higher plants and animals) and prokaryotic cells (cyanobacteria, $\gamma$ - and $\alpha$-Proteobacteria and some Firmicutes) $[10,11]$. To date, the presence of MTs has been reported among ciliated protozoa in only two genera (Tetrahymena and Paramecium) [12-17]. However, with regard to the putative Paramecium MT gene, no experimental data has been reported on its gene expression under metal stress [17]. Experiments on expression are therefore needed in order for it to be considered as a real MT. Attempts to classify MTs have been made by different authors. In 1999, Binz and Kägi [18] proposed a classification based on 15 families, defining one MT family for each main taxonomic group of organisms except fungi, to give six different sets. In this classification ciliate MTs are included in family 7 , which has been subsequently divided into two main subfamilies: 7a or cadmium-binding MTs (CdMTs) and 7b or copper-binding-MTs (CuMTs) [19]. At present, subfamily 7a includes $14 \mathrm{CdMTs}$ from different Tetrahymena species: two from T. pyriformis (TpyrMT-1 and TpyrMT-2) $[14,20]$, three from T. thermophila (TtheMTT1, TtheMTT3 and TtheMTT5) [19, 21], one from T. tropicalis (TtroMTT1) [22], one from T. rostrata (TrosMTT1) [23], one from T. pigmentosa (TpigMT-1) [15], one from $T$. vorax (TvorMT1), one from T. mobilis (TmobMT1) and four from $T$. hegewischi (ThegMT1, ThegMT2, ThegMT3 and ThegMT4) [16]. Subfamily 7b contains 7 CuMTs: two from T. thermophila (TtheMTT2 and TtheMTT4) [19, 24], one from T. pigmentosa (TpigMT-2) [15], two from T. tropicalis (TtropMT1 and TtropMT2), one from T. rostrata (TrosMTT2) [23] and one from an unspecified Tetrahymena sp1.7 (sp1.7-MT1). The two subfamilies differ mainly in their typical Cys residue clustering $[12,13]$.
Tetrahymena MTs have unique features with respect to MTs from other organisms. Their lengths (78-191 aa) and molecular masses $(8.2-20 \mathrm{KDa})$ are higher than MTs from vertebrates (25-82 aa; $2.5-8.0 \mathrm{KDa})$; therefore, they have a considerably higher number of Cys residues and a potentially larger metal binding capacity per MT molecule $[12,13,25]$. As detected in other organisms, a remarkably regular and hierarchical modular structural organization has been observed in Tetrahymena MTs, mainly CdMTs $[12,13,16,19]$. Several authors have proposed evolutionary history models for these MT genes, based on their modular and submodular structure and gene duplication as the main mechanism involved in MT evolution [12, 16, $19,26,27]$. In general, MT genes can be induced by an extensive range of different environmental biotic or abiotic stressors, such as metal(loid)s, oxidative agents, heat or cold shocks, hormones, cytokines, $\mathrm{pH}$ changes, starvation, and a large variety of organic chemicals or drugs. Likewise, Tetrahymena MT gene expression can be induced by very diverse stressors $[12,13,19,20,23,24]$.

In this study we report the cloning and characterization of 21 new MT genes (cDNAs) isolated from five Tetrahymena species never before analysed: T. borealis, T.elliotti, T.americanis, T. patula and T. malaccensis, selected from the two main taxonomic Tetrahymena groups (australis and borealis) [28]. Thereby increasing the CdMT sequences by about $46 \%$ and the CuMT sequences $56 \%$ in the Tetrahymena MT family, to give us a broader view of these highly conserved molecules. Furthermore, a new putative CuMT from the Tetrahymena related species and fish parasite Ichthyophthirius multifiliis has been incorporated into the actual in silico analysis of the MT sequence list (after exploration of its already sequenced macronuclear genome). Owing to the high nucleotide sequence identities among these MT genes, it has only been possible to analyze six of them by quantitative RT-PCR under different metal(loid)s and other environmental stressors.

\section{Results and discussion}

New Cd- and CuMTs from different Tetrahymena species

At present, there are about 42 known species of the genus Tetrahymena. These have been classified into two main groups: australis and borealis, according to the small subunit ribosomal gene (SSrRNA, 17-18S) [28]. At the same time, the borealis group is divided into three groups or ribosets: RSA1, RSA2 and RSB. In order to isolate new MT genes, Tetrahymena species from the SSrRNA phylogenetic tree were selected [28] to obtain a broader wide view of the biodiversity of these conserved genes. Table 1 , shows all the Tetrahymena MTs reported up to now, including the new MTs isolated in this study. So far, 13 Tetrahymena species have been analyzed ( $\sim 31 \%$ of the total known species): 9 from the Borealis group and 4 from the Australis group. From these, a total of $26 \mathrm{CdMT}$ and $15 \mathrm{CuMT}$ sequences 
Table 1 Present ciliate metallothioneins

\begin{tabular}{|c|c|c|c|c|}
\hline Taxonomic group & Ciliate species & $\mathrm{CdMT}$ & CuMT & Total \\
\hline \multirow[t]{5}{*}{ Borealis (RSA2) } & \multirow[t]{5}{*}{ T. borealis } & TborMTT1 $^{a}$ & TborMTT3 $^{a}$ & \multirow[t]{5}{*}{7} \\
\hline & & \multirow[t]{4}{*}{ TborMTT2 $^{\mathrm{a}}$} & TborMTT4 $4^{a}$ & \\
\hline & & & TborMTT6 ${ }^{\mathrm{a}}$ & \\
\hline & & & TborMTT7 ${ }^{\mathrm{a}}$ & \\
\hline & & & TborMTT8 ${ }^{\mathrm{a}}$ & \\
\hline \multirow[t]{2}{*}{ Borealis (RSA2) } & \multirow[t]{2}{*}{ T. elliotti } & TelliMTT1 ${ }^{a}$ & TelliMTT6 ${ }^{a}$ & \multirow[t]{2}{*}{4} \\
\hline & & TelliMTT2 $2^{\mathrm{a}}$ & TelliMTT8 ${ }^{a}$ & \\
\hline \multirow[t]{4}{*}{ Borealis (RSA1) } & \multirow[t]{4}{*}{ T. malaccensis } & TmalaMTT1 $^{\mathrm{a}}$ & \multirow[t]{4}{*}{ TmalaMTT5 ${ }^{a}$} & \multirow[t]{4}{*}{5} \\
\hline & & TmalaMTT2 $2^{\mathrm{a}}$ & & \\
\hline & & TmalaMTT3 $3^{\mathrm{a}}$ & & \\
\hline & & TmalaMTT4 $4^{\mathrm{a}}$ & & \\
\hline Borealis (RSA2) & T. mobilis & TmobMT1 & $?$ & 1 \\
\hline \multirow[t]{2}{*}{ Borealis (RSB) } & \multirow[t]{2}{*}{ T. pyriformis } & TpyrMT-1 & \multirow[t]{2}{*}{$?$} & \multirow[t]{2}{*}{2} \\
\hline & & TpyrMT-2 & & \\
\hline Borealis (RSA2) & T. rostrata & TrosMTT1 & TrosMTT2 & 2 \\
\hline \multirow[t]{3}{*}{ Borealis (RSA1) } & \multirow[t]{3}{*}{ T. thermophila } & TtheMTT1 & TtheMTT2 & \multirow[t]{3}{*}{5} \\
\hline & & TtheMTT3 & TtheMTT4 & \\
\hline & & TtheMTT5 & & \\
\hline \multirow[t]{2}{*}{ Borealis (RSA2) } & \multirow[t]{2}{*}{ T. tropicalis } & \multirow[t]{2}{*}{ TtroMTT1 } & TtropMT1 & \multirow[t]{2}{*}{3} \\
\hline & & & TtropMT2 & \\
\hline Borealis (RSB) & T. vorax & TvorMT1 & $?$ & 1 \\
\hline \multirow[t]{2}{*}{ Australis (RSC) } & \multirow[t]{2}{*}{ T. americanis } & TamerMTT1 $1^{\mathrm{a}}$ & \multirow[t]{2}{*}{ TamerMTT3 $^{\mathrm{a}}$} & \multirow[t]{2}{*}{3} \\
\hline & & TamerMTT2 $2^{\mathrm{a}}$ & & \\
\hline \multirow[t]{4}{*}{ Australis (RSC) } & \multirow[t]{4}{*}{ T. hegewischi } & ThegMT-1 & \multirow[t]{4}{*}{$?$} & \multirow[t]{4}{*}{4} \\
\hline & & ThegMT-2 & & \\
\hline & & ThegMT-3 & & \\
\hline & & ThegMT-4 & & \\
\hline Australis (RSC) & T. patula & TpatMTT1 $^{\text {a }}$ & $?$ & 2 \\
\hline & & TpatMTT2 $2^{\mathrm{a}}$ & & \\
\hline Australis (RSC) & T. pigmentosa & TpigMT-1 & TpigMT-2 & 2 \\
\hline Ichthyophthiriidae & I. multifiliis & $?$ & $\operatorname{ImMTT} 2^{\mathrm{a}}$ & 1 \\
\hline Total & 14 & 26 & 16 & 42 \\
\hline
\end{tabular}

${ }^{a}$ New Cd- or CuMTs reported in this study. RS: riboset. ? : unknown

have been reported (Table 1). In the present study, we incorporated 12 new CdMT cDNA sequences ( 46 \% more) and 9 new CuMT cDNA sequences ( $56 \%$ more), so thereby considerably increasing our knowledge of these conserved genes. Also included in this analysis was a new CuMT sequence from the ciliate parasite (that causes white spot disease in fresh water fishes) Ichthyophthirius multifiliis (taxonomically related to Tetrahymena, because both are located in the same Hymenostomatia subclass), giving a total of $16 \mathrm{CuMT}$ sequences considered in this study (Table 1). Of the new CdMT cDNA sequences, one (TmalaMTT1) is identical to the previously reported TmalMT1, also isolated from the T.malaccensis [16]. However, in this putative cDNA [GenBank: HQ166894] 5'or 3'UTRs have not been reported, while our TmalaMTT1 cDNA already presents both UTR regions [GenBank: KU167646].

Ciliate MTs (family 7) [18] have been divided into two subfamilies: 7a (CdMTs) and 7b (CuMTs) [19]. An updated phylogenetic tree drawn up to include the new inferred amino acid sequences from all the new ciliate MT genes (Fig. 1), confirms the previous classification into two large groups or subfamilies: CdMTs and CuMTs. This is due to the strict Cys residue patterns or modular configuration of these proteins in both MT groups (Figs. 2 and 3). Although the CuMT sequence from I. multifiliis (ImMTT2) is clearly separated from the rest of the Tetrahymena CuMTs, it is completely integrated in the CuMT group or subfamily (Fig. 1). In general, MTs from the same Tetrahymena species are located close together in the tree, although this is not always the case. This may indicate a certain convergent evolution of these genes into the Tetrahymena genus, or a common ancestor gene structure which originated very similar proteins through the different Tetrahymena species.

\section{Cysteine patterns}

Cysteine (Cys) residues are the main amino acids in MT composition because they are the chelating points for metals, forming metal-thiolate clusters [29, 30]. The total amount of Tetrahymena MT Cys residues is considerable (up to 54 residues for CdMTs) (Table 2), due to the longer length of these molecules with respect to standard MTs. However, the average Cys percentage of these MTs lies within the average Cys percentage values for standard MTs (7-21 Cys residues) (Table 2). Traditional Cys (C) clusters appear in Tetrahymena CdMTs as in standard MTs, such as: XCCX (34.94 \%), CXC (10.72\%) and XXCXX or non-clustered Cys (4.16 \%) (Table 2). In addition, they have other Cys clusters that are almost exclusive to Tetrahymena CdMTs: CCC (32.44 \%), CXCC (16.91\%) or CXCXC (0.83\%) (where "X" is any other amino acid different to Cys) (Table 2). These unusual Cys clusters also appear in the MTs of certain other organisms, such as the annelid Eisenia foetida (CCC) [GenBank: P81695], the yeast Yarrowia lipolytica (CCC) [GenBank: Q9HFD0], the arthropod Callinectes sapidus (CCC and CXCC) [GenBank: AAF08966], the mollusk Crassostrea virginica (CCC and CXCC) [GenBank: AAZ94898], the American lobster Homarus americanus(CXCC) [GenBank: P29499], the amphibious Xenopus laevis(CXCC) [GenBank: AAB60616], the yeast Saccharomyces cerevisiae (CXCXC) [GenBank: AAA66061], the nematode Caenorhabditis elegans (CXCXC) [GenBank: P17511] and the purple sea urchin Strogylocentrotus purpuratus (CXCC) [GenBank: P04734]. In Tetrahymena CdMTs, CCC and XCCX are the most abundant clusters (Table 2). However, in ciliate CuMTs CCC, CXCC and CXCXC clusters are almost 


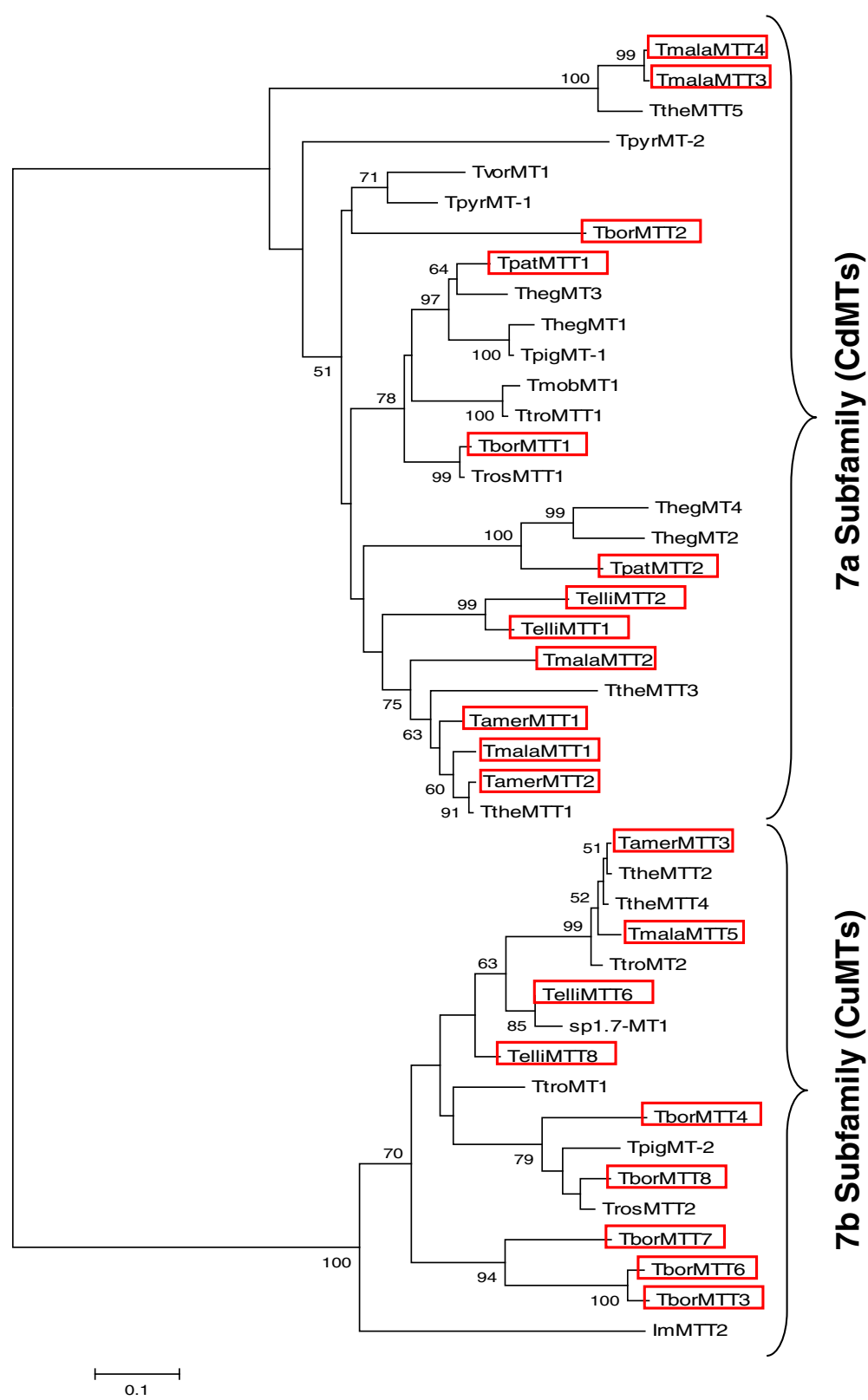

Fig. 1 Phylogenetic tree of all ciliate metallothioneins. Two well defined groups corresponding to both MT subfamilies are observed. Multiple alignments of amino acid sequences were obtained by using the T-Coffee program. Numbers indicate bootstrap values ( $<50 \%$ are not shown) from 2000 replicates. Brach lengths are drawn to scale as indicated by the scale bar. The names of the new MT sequences reported in this paper are indicated into the red boxes. See Table 1 for ciliate species identification

absent (Table 2). On the other hand, the predominant cluster in these CuMTs is CXC (92.34\%), as in MTs from other organisms.

Another structural feature differentiating both Tetrahymena MT subfamilies is the relation between Lys and Cys residues along the polypeptide backbone. Lys residues also seem to have an important role in these proteins because Cys reactivity depends on the proximity of these basic amino acids. In ciliate CuMTs (subfamily 7b), as in mammalian MTs, Lys (K) residues are usually contiguous to Cys residues. Furthermore, the great majority of CXC motifs in CuMTs are CKC clusters (Fig. 2). On the other hand, in Tetrahymena CdMTs (subfamily $7 \mathrm{a})$ the CKC clusters are less frequent and normally limited to the $\mathrm{C}$-terminal regions of the type 2 submodules (Fig. 3). At physiological pH, Lys residues are positively charged, and it has been reported [31] that the presence of these adjacent basic residues considerably decreases 


\begin{tabular}{|c|c|c|}
\hline CuMTs & & agth \\
\hline TpigMT-2 & MDTQTQTKLTTACKCNPCKCQPLCKCGTTSACNCQPCE-------------- & 38 \\
\hline TthеMTT2 & MDTQTQTKVTVGCSCNPCKCQPLCKCGTTAACNCQPCE----.---.-. & 38 \\
\hline TtheMTT4 & MDTQTQTKVTVGCSCNPCKCQPLCKCGTTAACNCQPCE-------------- & 38 \\
\hline TrosMTT2 & 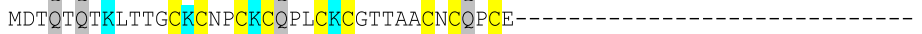 & 38 \\
\hline TtropMT1 & 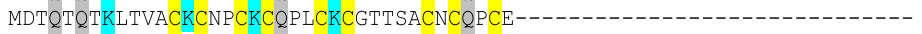 & 38 \\
\hline TtropMT2 & 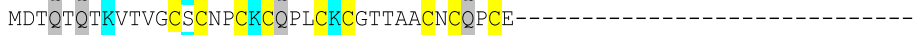 & 38 \\
\hline sp1.7-MT1 & 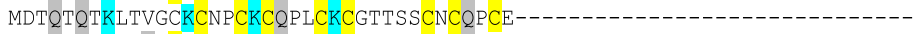 & 38 \\
\hline TborMTT3 3 & 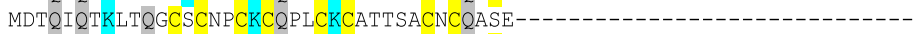 & 38 \\
\hline TborMTT4 & 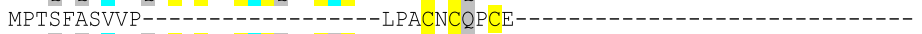 & 20 \\
\hline TborMTT6 & 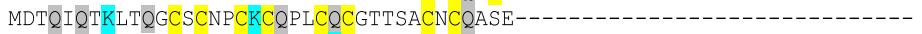 & 38 \\
\hline TborMTT7 & 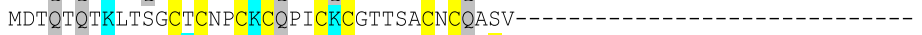 & 38 \\
\hline TborMTT8 & 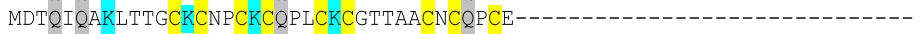 & 38 \\
\hline TamerMTT3 & 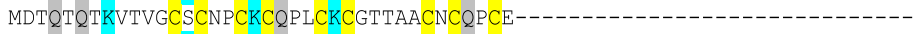 & 38 \\
\hline Tellimtт6 & MDTQTQTKLTVGCKCNPCKCQPLCKCGTTSSCNCQPCE-- & 38 \\
\hline TelliMTT8 & 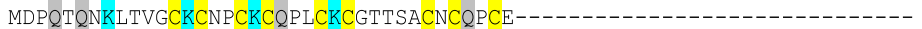 & 38 \\
\hline TmalaMTT5 & 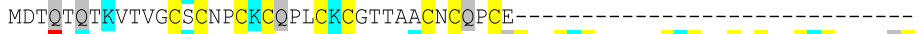 & 38 \\
\hline ImMTT2 & MES IUSK---TAACKCNPCNCNP-CKCGTTAKCNCNNCQCNPCKCGTTAACKCNPCGCNPCKCGTTAQC & 64 \\
\hline TpigMT-2 & NCDPCSCNPCKCGTSDACKCNPCKCTDCKCAA - & 32 \\
\hline TtheмTT2 & NCDPCSCNPCKCGATESCGCNPCKCAECKCGS & 36 \\
\hline TtheMTT4 & NCDPCSCNPCKCGVTESCGCNPCKCAECKCGSHTEK----- & 36 \\
\hline TrOSMTT2 & NCDPCNCNPCKCGVSDGCKCNPCKCADCKCT & 31 \\
\hline TtropMT1 & NCDPCSCNPCKCGTSEACKCNPCKCAECKCGSATDK- & 36 \\
\hline TtropMT2 & 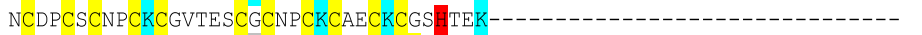 & 36 \\
\hline sp1.7-MT1 & NCDPCSCNPCKCGATESCQCNPCKCAECKCCT HAVK-- & 36 \\
\hline TborMTT3 & NSDACACNPCKCGVSGTCKCNPCQCVDCKCGTASQQNVGCKCDTCACNPCRCGVSDACQCNTCKCGD & 67 \\
\hline TborMTT4 & NCDPCNCNPCKCGSDGCKCNPCKCADCKCT & 31 \\
\hline TborMTT6 & NSDACTCNPCKCGVSGTCKCNPCSCVDCKCGTASQQSVGCKCDTCACNPCKCGVSDACQCNTCKCGD & 67 \\
\hline TborMTT7 & DNEACSCNPCKCGVTSSCQCNPCKCGDCKCGAVSQVTAGCKCNPCSCNPCKCGVSASCSCSSCQCSD & 67 \\
\hline TborMTT8 & NCDPCNCNPCKCGVSDGCKCNPCKCADCKCT- & 31 \\
\hline TamerMTT3 & DPCSCNPCKCGATESCGCNPCKCAECKCGS HTEK- & 36 \\
\hline TellimTT6 & NCDPCSCNPCKCGATE SCSCNPCKCAECKCGT DVKTSACKCDPCSCNPCKCGVTQSCQCNPCTCAE & 67 \\
\hline TellimTt8 & NCDPCSCNPCKCGATENCQCNPCKCAECKCGN HAAK- & 36 \\
\hline TmalaMTT5 & NCDPCSCNPCKCGATESCGCNPCKCAECKCGSHAEK & 36 \\
\hline ImMTT2 & NCTNCQCNPCRCGTTAQCKCNPCGCNPCKCGTTAQ----CNCTNCQCNPCRCG-------------- & 49 \\
\hline TpigMT-2 & ---------------------------SAGCKCSPCNCTDCKCTGTESC-C--------QKQ & 26 \\
\hline TtheMTT2 & $-------T S A C K C N P C A C N P C N C G S T S N C K C N P C K C A E C K C$ & 34 \\
\hline TtheMTT4 & --------TSACKCNPCACNPCKCGSTSNCKCNPCKCAECKC & 34 \\
\hline TrOSMTT2 & - & \\
\hline TtropMT1 & 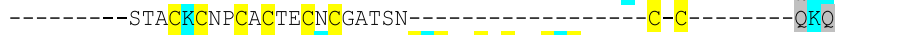 & 26 \\
\hline TtropMT2 & --------TSACKCNPCACNPCKCGSTSNCKCTPCNCAECKC & 34 \\
\hline $\mathrm{sp} 1.7-\mathrm{MT} 1$ & --------TSACKCDPCSCNPCKCGVTQSCQCNPCTCAECKC & 34 \\
\hline TborMTT3 & CKCGSVSQQTAGCKCNPCTCNNCKCGVSASCKCNPCKCADCKCSGSESC-C--------QKQ & 53 \\
\hline TborMTT4 & -1 & \\
\hline TborMTT6 & CKCGSVSQQTAGCKCNPCTCNNCKCGVSASCKCNPCKCVDCKCSGSESC-C--------QKQ & 53 \\
\hline TborMTT7 & CKCGTVSQATVGCKCNPCTCNPCKCGVSASCKCNPCKCANCNCS & 44 \\
\hline TborMTT8 & $-{ }_{1}$ & 9 \\
\hline TamerMTT3 & --------TSACKCNPCACNPCNCGSTSNCKCNPCKCAECK & 33 \\
\hline TelliмTт6 & CKCGTIIISASTSACKCNPCTCNPCKCGVTSNCKCNPCGCSECKC & 43 \\
\hline TellimTT8 & --------TSACKCNPCGCSECKC & 16 \\
\hline TmalaMTT5 & --------TSTCKCNPCTCNPCKCGSTSNCKCNPCKCAECKC & 34 \\
\hline ImMTT2 & --------TTAQCKCNPCGCNPCKCGTTAQCNCTNCQCNPCKCGTTDNCKCGNGCQCNPCKC & 54 \\
\hline
\end{tabular}

Fig. 2 Molecular structure of subfamily 7b (CuMTs). Multiple alignments were made using the T-Coffee program, followed by visual inspection and manual adjustment. The new CuMT sequences reported in this paper are indicated with colored (orange) names. Yellow shaded regions indicate conserved Cys (C) residues. Blue and grey shaded regions indicate Lys $(K)$ or $G \ln (Q)$ residues, respectively. His (H) residues are indicated by red shading. See the text for further explanation

the pK value thus decreasing the reactivity of Cys residues. Therefore, it is possible that Tetrahymena CuMTs may have a certain metal buffering capacity that differs from the one theoretically assigned to them.

\section{Modular/submodular structure of the subfamily $7 a$ (CdMTs)}

The highly conserved Cys residue locations in Tetrahymena CdMT sequences define a strict modular/submodular structure in all of these proteins [19] (Fig. 3).
Each module was initially defined by the rule that every segment (with several exceptions) carries a CXCCX motif at its $\mathrm{C}$-terminus, the last " $\mathrm{X}$ " being a Lys (K) or Glutamine (Q) residue (Fig. 3). Module lengths vary from 32 to 63 amino acids and are separated by linkers of 2-9 amino acids (Fig. 3). The number of modules per MT molecule is from 2 to 5 , so at present 9 CdMTs have only two modules (bi-modular structure): TpyrMT-1, TtheMTT5, TrosMTT1, TpigMT-1, ThegMT1, TborMTT1, TmalaMTT4, TpatMTT1 and TamerMTT1. The majority (13) 


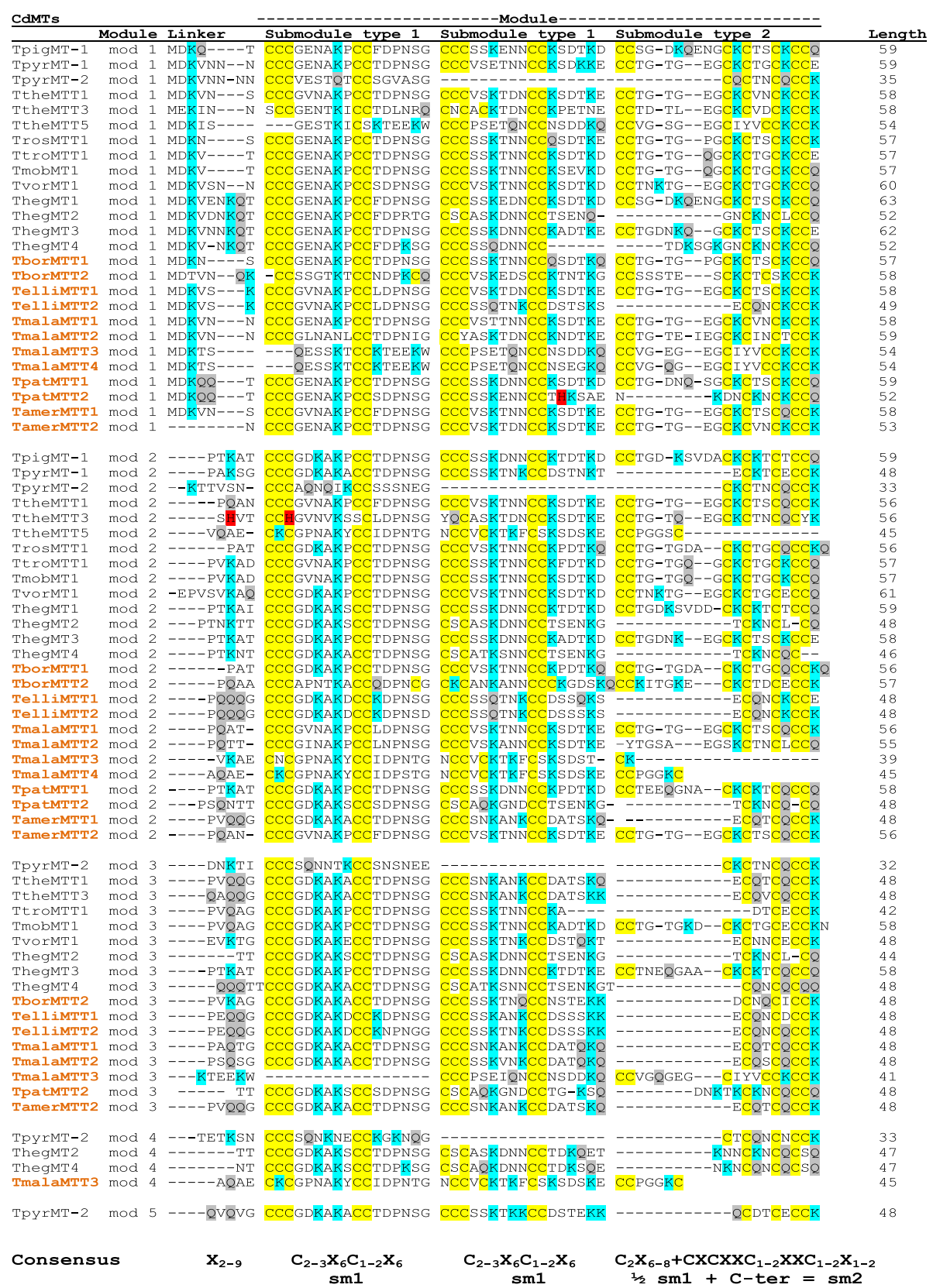

Fig. 3 Modular structure of subfamily 7a (CdMTs). Multiple alignments were made using the T-Coffee program, followed by visual inspection and manual adjustment. The new CdMT sequences reported in this paper are indicated with colored (orange) names. Yellow shaded regions indicate conserved Cys $(\mathrm{C})$ residues. Blue and grey shaded regions indicate Lys $(\mathrm{K})$ or $\mathrm{Gln}(\mathrm{Q})$ residues, respectively. His $(\mathrm{H})$ residues are indicated by red shading. sm1: submodule-1, sm2: submodule-2. See the text for further explanation

have a tri-modular structure: TtheMTT1, TtheMTT3, TtroMTT1, TvorMT1, TmobMT1, ThegMT3, TborMTT2, TelliMTT1, TelliMTT2, TmalaMTT1, TmalaMTT2, TpatMTT2 and TamerMTT2; only 3 of them (TmalaMTT3, ThegMT2 and ThegMT4) have four modules (tetra-modular), and only one (TpyrMT-2) has five modules (penta-modular) (Fig. 3). As shown in Fig. 4, the $18 \mathrm{~S}$ rRNA phylogenetic tree of the 13 Tetrahymena species analysed separates them into Borealis and Australis groups. Although the species analyzed from the Australis group are still scarce, we detect a certain tendency towards a CdMT tri-modular structure in the Borealis group species with respect to the Australis group (Fig. 4). This could mean that the CdMT tri-modular structure might be more similar to the ancestral CdMT common structure for the Tetrahymena genus. 
Table 2 Distribution of Cys clusters among Tetrahymena MTs

\begin{tabular}{|c|c|c|c|c|c|c|c|c|c|}
\hline $\mathrm{CdMT}$ & CCC & CXCC & $C X C X C$ & $x C C X$ & $C X C$ & $X X C X X$ & Total Cys & $\%$ Cys $^{(a)}$ & Length \\
\hline TpigMT-1 & 4 & 2 & 0 & 6 & 2 & 0 & 34 & 28.81 & 118 \\
\hline TpyrMT-1 & 4 & 2 & 0 & 5 & 1 & 1 & 31 & 28.97 & 107 \\
\hline TpyrMT-2 & 6 & 5 & 0 & 6 & 4 & 1 & 54 & 29.83 & 181 \\
\hline TtheMTT1 & 6 & 3 & 0 & 8 & 2 & 1 & 48 & 29.63 & 162 \\
\hline TtheMTT3 & 2 & 2 & 1 & 9 & 3 & 3 & 42 & 25.93 & 162 \\
\hline TtheMTT5 & 1 & 1 & 0 & 5 & 1 & 6 & 24 & 24.24 & 99 \\
\hline TrosMTT1 & 4 & 2 & 0 & 6 & 2 & 0 & 34 & 30.09 & 113 \\
\hline TtroMTT1 & 6 & 3 & 0 & 8 & 2 & 0 & 47 & 30.13 & 156 \\
\hline TmobMT1 & 6 & 3 & 0 & 9 & 3 & 0 & 51 & 29.65 & 172 \\
\hline TvorMT1 & 6 & 3 & 0 & 8 & 2 & 1 & 48 & 28.40 & 169 \\
\hline ThegMT1 & 4 & 2 & 0 & 6 & 2 & 0 & 34 & 27.87 & 122 \\
\hline ThegMT2 & 4 & 1 & 0 & 8 & 7 & 4 & 49 & 25.65 & 191 \\
\hline ThegMT3 & 6 & 3 & 0 & 9 & 3 & 0 & 51 & 28.65 & 178 \\
\hline ThegMT4 & 5 & 1 & 0 & 8 & 6 & 4 & 50 & 25.91 & 193 \\
\hline TborMTT1 & 4 & 2 & 0 & 6 & 2 & 0 & 34 & 30.09 & 113 \\
\hline TborMTT2 & 5 & 2 & 2 & 9 & 1 & 2 & 49 & 30.06 & 163 \\
\hline TelliMTT1 & 6 & 3 & 0 & 7 & 1 & 2 & 45 & 29.22 & 154 \\
\hline TelliMTT2 & 6 & 3 & 0 & 6 & 0 & 3 & 42 & 28.97 & 145 \\
\hline TmalaMTT1 & 6 & 3 & 0 & 8 & 2 & 1 & 48 & 29.63 & 162 \\
\hline TmalaMTT2 & 5 & 3 & 0 & 8 & 1 & 2 & 44 & 27.16 & 162 \\
\hline TmalaMTT3 & 2 & 2 & 0 & 12 & 2 & 6 & 46 & 25.70 & 179 \\
\hline TmalaMTT4 & 1 & 1 & 0 & 7 & 1 & 3 & 25 & 25.25 & 99 \\
\hline TpatMTT1 & 4 & 2 & 0 & 6 & 2 & 0 & 34 & 29.06 & 117 \\
\hline TpatMTT2 & 4 & 2 & 0 & 6 & 3 & 3 & 39 & 26.35 & 148 \\
\hline TamerMTT1 & 4 & 2 & 0 & 5 & 1 & 1 & 31 & 29.25 & 106 \\
\hline TamerMTT2 & 6 & 3 & 0 & 8 & 2 & 1 & 48 & 30.57 & 157 \\
\hline Total Cys ${ }^{(b)}$ & 351 & 183 & 9 & 378 & 116 & 45 & 1082 & 28.27 & 147 \\
\hline$\%$ Cys $^{(\mathrm{c})}$ & 32.4 & 16.9 & 0.8 & 34.9 & 10.7 & 4.1 & 100 & & \\
\hline \multicolumn{10}{|l|}{ CuMT } \\
\hline TpigMT-2 & 0 & 0 & 0 & 1 & 12 & 2 & 28 & 29.17 & \\
\hline TtheMTT2 & 0 & 0 & 0 & 0 & 15 & 2 & 32 & 29.63 & 96 \\
\hline TtheMTT4 & 0 & 0 & 0 & 0 & 15 & 2 & 32 & 29.63 & 108 \\
\hline TrosMTT2 & 0 & 0 & 0 & 1 & 9 & 2 & 22 & 28.21 & 108 \\
\hline TtroMT1 & 0 & 0 & 0 & 1 & 12 & 2 & 28 & 28.00 & 78 \\
\hline TtroMT2 & 0 & 0 & 0 & 0 & 15 & 2 & 32 & 26.63 & 100 \\
\hline sp1.7-MT1 & 0 & 1 & 0 & 0 & 14 & 1 & 32 & 26.63 & 108 \\
\hline TelliMTT6 & 0 & 0 & 0 & 0 & 21 & 2 & 44 & 29.73 & 108 \\
\hline TelliMTT8 & 0 & 0 & 0 & 0 & 12 & 2 & 26 & 28.89 & 148 \\
\hline TmalaMTT5 & 0 & 0 & 0 & 0 & 15 & 2 & 32 & 29.63 & 90 \\
\hline TborMTT3 & 0 & 0 & 0 & 1 & 21 & 0 & 44 & 27.85 & 108 \\
\hline TborMTT4 & 0 & 0 & 0 & 1 & 6 & 2 & 16 & 26.67 & 158 \\
\hline TborMTT6 & 0 & 0 & 0 & 1 & 21 & 0 & 44 & 27.85 & 60 \\
\hline TborMTT7 & 0 & 0 & 0 & 0 & 21 & 0 & 42 & 28.19 & 158 \\
\hline TborMTT8 & 0 & 0 & 0 & 1 & 9 & 2 & 22 & 28.21 & 149 \\
\hline
\end{tabular}


Table 2 Distribution of Cys clusters among Tetrahymena MTs (Continued)

\begin{tabular}{|c|c|c|c|c|c|c|c|c|c|}
\hline TamerMTT3 & 0 & 0 & 0 & 0 & 14 & 3 & 31 & 28.97 & 78 \\
\hline ImMTT2 & 0 & 0 & 0 & 0 & 27 & 0 & 54 & 32.34 & 107 \\
\hline Total Cys ${ }^{(b)}$ & 0 & 3 & 0 & 14 & 518 & 26 & 561 & 28.60 & 167 \\
\hline$\% \mathrm{Cys}^{(\mathrm{c})}$ & 0 & 0.5 & 0 & 2.5 & 92.3 & 4.6 & 100 & & 113 \\
\hline
\end{tabular}

New MTs reported in this study are in bold text. A cluster is defined as any group of contiguous residues in which any two Cys residues are separated from one another by, at most, any other amino acid (X). ${ }^{\text {(a) }}$ Percentage of Cys residues in the complete MT. ${ }^{\text {(b) }}$ Total Cys residues/cluster type. ${ }^{(c)}$ Percentage of Cys residues/cluster type

These modules are made up of two types of submodules: Type 1 submodules (sm1) have the consensus sequence $\mathrm{C}_{2-3} \mathrm{X}_{6} \mathrm{C}_{1-2} \mathrm{X}_{6}$ (with few exceptions), while complete Type 2 submodules ( $\mathrm{sm} 2$ ) can be represented as $\mathrm{C}_{2} \mathrm{X}_{6-8}+\mathrm{CXCXXC}_{1-2} \mathrm{XXC}_{1-2} \mathrm{X}_{1-2}$ (Fig. 3). Sm2 represents approximately the final half of the Type 1 submodules $\left(\mathrm{C}_{2} \mathrm{X}_{6-8}\right)$, plus a quite conserved $\mathrm{C}$-terminal region, where the last "X" is $\mathrm{K}$ (Lys) $55 \%$, Q (Gln) $36 \%$, E (Glu) $7 \%$ or $\mathrm{N}(\mathrm{Asn}) \sim 1.5 \%$. Approximately $47 \%$ of sm 2 are incomplete; $42 \%$ only present the C-terminal region, while $\sim 5 \%$ of them have only half the $\operatorname{sm} 1(1 / 2 \mathrm{sm} 1)$ (Fig. 3). In most cases ( $54 \%)$, these modules are made up of two complete sm1 and one complete sm2, but a $34 \%$ of them present incomplete modules, such as TpyrMT-2 (with four modules formed by only one sm1 and half of sm2). Despite the fact that Tetrahymena CuMTs do not present such clear modular structure, their consensus sequence $\mathrm{CKCX}_{2-5} \mathrm{CXC}$ is repeated multiple times (where in a few cases Lys $(\mathrm{K})$ may be substituted by another amino acid) (Fig. 2). Therefore, a structural organization based on these repeats should also be considered [13].

Gene duplication is one of the main phases in the generation and evolution of new genes and seems to be the main mechanism involved in the evolution of these proteins, as several authors have noted [32-34]. Given the clear modular structure of Tetrahymena CdMTs and the highly conserved Cys repeats in both subfamilies, we might suppose that successive gene duplication events and subsequent specialization could be the main mechanisms involved in the evolution of these ciliate MTs. Therefore, the gene duplication hypothesis, already considered for Tetrahymena MTs [12, 13, 19, 26, 27], is the most credible mechanism for explaining the evolution of these proteins. A model that attempts to explain the evolutionary history of Tetrahymena MTs has been described in [12]. It is based on the hypothesis that both MT subfamilies were constructed from an ancestral module, containing the $\mathrm{C}_{3} \mathrm{X}_{6}$ motif (half of sm1), which was duplicated many times as a result of episodes of gradual environmental pollution. Therefore, both paralog duplications into the same species (several CdMT or CuMT gene isoforms are present in each species) and many orthologs could have been created in different related Tetrahymena species, giving rise to those MT isoforms that are currently known to us.

An example of a probable semi-complete duplication of a CdMT gene originating a new CdMT isoform in the same species, can be observed in CdMT genes from T. malaccensis (Fig. 5). Two copies of the TmalaMTT4 gene isoform

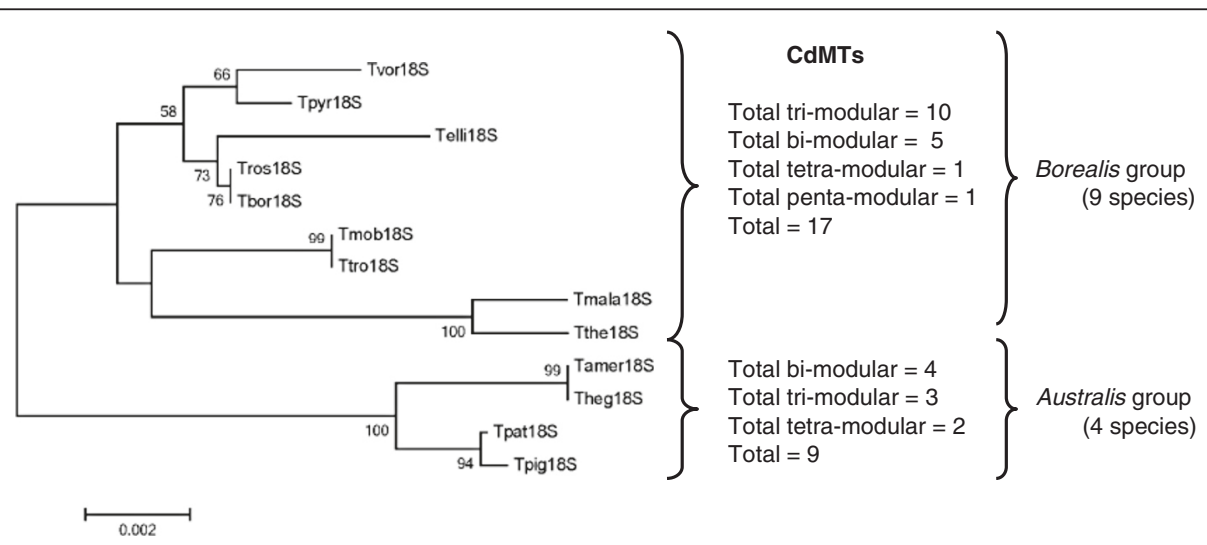

Fig. 4 Phylogenetic tree (18S rRNA) of Tetrahymena species with reported CdMTs and their modular structures. Two well defined ribo-groups corresponding to both taxonomical groups were obtained. Multiple alignments of ribo-nucleotide sequences were obtained by using the T-Coffee program. Numbers indicate bootstrap values from 2000 replicates. Branch lengths are drawn to scale as indicated by the scale bar. The number of bi-, tri-, tetra- or penta- modular structures of CdMTs are indicated for each Tetrahymena group. See Table 1 for ciliate species identification 


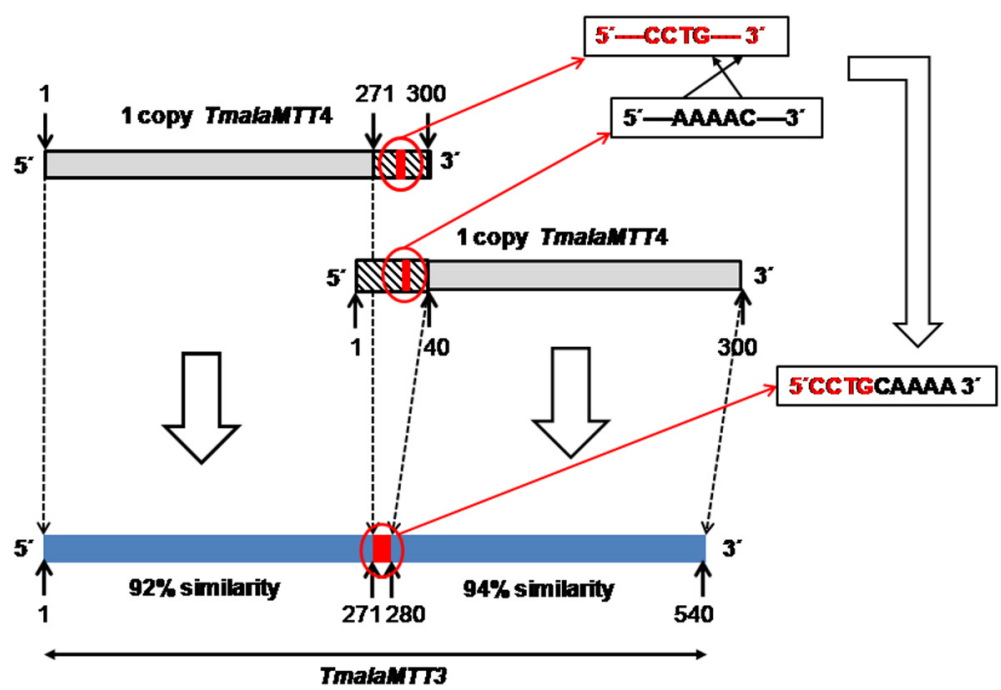

Fig. 5 Schematic representation of TmalaMTT3 gene origin from TmalaMTT4 gene duplication. $5^{\prime}$ and 3' striped sections show the eliminated regions (after recombination) of both TmalaMTT4 gene copies. The red boxes in the striped sections from each TmalaMTT4 gene copy and in the TmalaMTT3 gene represent nucleotides forming the junction between both copies. Numbers indicate the nucleotide location. See the text for explanation

(300 bp of length) seem to have been involved in the creation of the TmalaMTT3 gene (540 bp). A recombination process seems to have occurred between a 29 bp region from the 3' end of one TmalaMTT4 gene copy and a $40 \mathrm{bp}$ region from the 5'end of a second copy of this same gene, together with the elimination of $60 \mathrm{bp}$ from both gene copies, resulting in the origination of the junction area (9 bp) between both TmalaMTT4 gene copies (Fig. 5). This 9 bp new sequence is formed by four nucleotides from one TmalaMTT4 copy ( 3 'end) and 5 inverted nucleotides from the other gene copy (5'end). Therefore, the TmalaMTT3 gene is composed of a first uncompleted copy (271 bp) of the TmalaMTT4 gene, a junction region $(9 \mathrm{bp})$ originated after recombination and elimination, and a second uncompleted copy (260 bp) of the TmalaMTT4 gene (Fig. 5). Through evolution, these uncompleted TmalaMTT4 copies have suffered some degree of gene diversification, so each of them currently presents 92 and $94 \%$ identity, respectively, with respect to the corresponding section of the original TmalaMTT4 gene sequence (Fig. 5).

\section{Asymmetry of the codon usage for glutamine residues: phylogenetic implications}

Glutamines (Q) are important residues for MTs because they are also involved in stabilizing the metal-protein complex [35]. Ciliates use a particular genetic code, because the UAA and UAG codons, which are universal stop codons in many organisms, codify the amino acid glutamine (Gln), UGA being the only stop codon used by these eukaryotic microorganisms (barring some exceptions) [36, 37]. Almost all ciliate MTs (except TpyrMT-1) contain Q residues (from 2 in TborMTT4 to 17 in ThegMT-4) (Table 3). In general,
Tetrahymena CdMTs have more Q residues than CuMTs (Table 3). In a previous study [12] it was hypothesized that Gln residues were only codified by CAA codons in Tetrahymena CuMTs. However, after analyzing 10 new ciliate CuMTs, we have detected that this is not necessarily the case. Although the universal CAA codon is predominant in CuMTs (61.32\%), it is not the only one encoding Gln (29.24 \% UAA, 7.55 \% UAG and 1.89 \% CAG) (Table 3). On the other hand, Tetrahymena CdMTs mainly use the UAA codon to codify this amino acid (53.93\%), together with other codons (29.21 \% CAA; $17.17 \%$ UAG and $1.69 \%$ CAG) (Table 3). Moreover, in CdMTs these UAA codons are primarily located in liker regions (30.3\%) and at the end of sm2 (40.5\%). The total ratio of non-canonical (UAA + UAG)/canonical (CAA + CAG) Gln codons for Tetrahymena CdMTs is $123 / 55=2.23$ (that is, almost twice as many non-canonical as canonical codons). The opposite is true for CuMTs, however, where this ratio is $39 / 67=0.58$ or the inverse $67 / 39=1.71$ (almost twice as many canonical as non-canonical codons). Interestingly, only two CdMTs sequences (TtheMTT3 and ThegMT4) use the four possible Gln codons (Table 3). This drastic asymmetry in codon usage for Gln residues again corroborates the fact that Tetrahymena CuMTs are more similar to standard MTs. Likewise, it shows another important difference between both MT subfamilies.

From a phylogenetic point of view, which we reported in a previous review article [12], it seems CuMTs are diverged earlier than CdMTs as it has been reported that rather than resulting from a single ancient event, these genetic code deviations arose independently several times within the phylum Ciliophora [36, 37]. Also, if 
Table 3 Distribution of glutamine codons in both ciliate MT subfamilies

\begin{tabular}{|c|c|c|c|c|c|}
\hline \multirow[t]{2}{*}{ CdMT } & \multicolumn{5}{|c|}{ Glutamine codons } \\
\hline & CAA & UAA & UAG & CAG & Total \\
\hline TpigMT-1 & 3 & 1 & 0 & 0 & 4 \\
\hline TpyrMT-1 & 0 & 0 & 0 & 0 & 0 \\
\hline TpyrMT-2 & 2 & 10 & 2 & 0 & 14 \\
\hline TtheMTT1 & 2 & 4 & 1 & 0 & 7 \\
\hline TtheMTT3 & 2 & 5 & 1 & 1 & 9 \\
\hline TtheMTT5 & 2 & 1 & 0 & 0 & 3 \\
\hline TrosMTT1 & 2 & 2 & 0 & 0 & 4 \\
\hline TtroMTT1 & 3 & 1 & 0 & 0 & 4 \\
\hline TmobMT1 & 4 & 1 & 0 & 0 & 5 \\
\hline TvorMT1 & 4 & 0 & 0 & 0 & 4 \\
\hline ThegMT1 & 2 & 2 & 0 & 0 & 4 \\
\hline ThegMT2 & 2 & 4 & 2 & 0 & 8 \\
\hline ThegMT3 & 1 & 3 & 0 & 1 & 5 \\
\hline ThegMT4 & 1 & 10 & 5 & 1 & 17 \\
\hline TborMTT1 & 2 & 4 & 0 & 0 & 6 \\
\hline TborMTT2 & 3 & 3 & 1 & 0 & 7 \\
\hline TelliMTT1 & 1 & 6 & 2 & 0 & 9 \\
\hline TelliMTT2 & 3 & 5 & 3 & 0 & 11 \\
\hline TmalaMTT1 & 1 & 5 & 1 & 0 & 7 \\
\hline TmalaMTT2 & 3 & 3 & 1 & 0 & 7 \\
\hline TmalaMTT3 & 2 & 5 & 0 & 0 & 7 \\
\hline TmalaMTT4 & 0 & 5 & 0 & 0 & 5 \\
\hline TpatMTT1 & 2 & 4 & 1 & 0 & 7 \\
\hline TpatMTT2 & 2 & 4 & 5 & 0 & 11 \\
\hline TamerMTT1 & 1 & 4 & 1 & 0 & 6 \\
\hline TamerMTT2 & 2 & 4 & 1 & 0 & 7 \\
\hline Total $(\%)^{a}$ & $52(29.21 \%)$ & 96 (53.93 \%) & $27(15.17 \%)$ & $3(1.69 \%)$ & 178 (100\%) \\
\hline \multicolumn{6}{|l|}{ CuMT } \\
\hline TpigMT-2 & 6 & 0 & 0 & 0 & 6 \\
\hline TtheMTT2 & 4 & 0 & 0 & 0 & 4 \\
\hline TtheMTT4 & 4 & 0 & 0 & 0 & 4 \\
\hline TrosMTT2 & 5 & 0 & 0 & 0 & 5 \\
\hline TtroMT1 & 5 & 0 & 0 & 1 & 6 \\
\hline TtroMT2 & 2 & 0 & 1 & 1 & 4 \\
\hline Sp1.7-MT1 & 3 & 2 & 2 & 0 & 7 \\
\hline TelliMTT6 & 5 & 1 & 0 & 0 & 6 \\
\hline TelliMTT8 & 3 & 2 & 0 & 0 & 5 \\
\hline TmalaMTT5 & 3 & 1 & 0 & 0 & 4 \\
\hline TborMTT3 & 4 & 7 & 2 & 0 & 13 \\
\hline TborMTT4 & 2 & 0 & 0 & 0 & 2 \\
\hline TborMTT6 & 4 & 7 & 2 & 0 & 13 \\
\hline TborMTT7 & 5 & 2 & 1 & 0 & 8 \\
\hline TborMTT8 & 5 & 0 & 0 & 0 & 5 \\
\hline
\end{tabular}


Table 3 Distribution of glutamine codons in both ciliate MT subfamilies (Continued)

\begin{tabular}{llllll}
\hline TamerMTT3 & 4 & 0 & 0 & 0 & 4 \\
ImMTT2 & 1 & 9 & 0 & 0 & 10 \\
Total $\left.^{(\%)}\right)^{\text {a }}$ & $\mathbf{6 5 ( 6 1 . 3 2} \%)$ & $\mathbf{3 1}(\mathbf{2 9 . 2 4} \%)$ & $\mathbf{8}(\mathbf{7 . 5 5} \%)$ & $\mathbf{2}(\mathbf{1 . 8 9} \%)$ & $\mathbf{1 0 6}(\mathbf{1 0 0} \%)$
\end{tabular}

New MTs reported in this study are in bold text. ${ }^{\text {a }}$ Total glutamine residues using a type of codon and percentage

these changes occurred in the tRNA(Gln) gene(s) of an ancestral ciliate using the standard genetic code, we would have to assume that Tetrahymena CuMTs appeared before CdMTs (which use mainly UAA codons). This agrees with the assumption, supported by several authors, that two early MT lineages $(\mathrm{Cu}$ and $\mathrm{Zn}$ thioneins) were already present in the early phases of eukaryotic evolution [32]. It appears that early on in evolution, the primary function of MTs was to bind to physiologically important or essential metals (such as $\mathrm{Cu}$ or $\mathrm{Zn}$ ). Accordingly, the appearance and evolution of MTs was probably not dictated by Cd, although with the evolution of higher life forms, MTs became more indispensable for protecting against $\mathrm{Cd}$ and other nonessential metals than for performing other suggested functions [4].

\section{Other interesting features of Tetrahymena MTs}

Tetrahymena MTs are considerably longer (60-193 aa) than standard ones $(25-82$ aa). Of the ciliate CdMTs and CuMTs, the longest are ThegMT4 (193 aa) and ImMTT2 (167 aa) or TborMTT3 and TborMTT6 (158 aa each), respectively (Table 2). The length they reach is therefore more than double that of the longest standard MTs. Despite having the longest MTs and a higher number of Cys residues, the Cys \% lies within the range for standard MTs (16-32 \%) (Table 2). However, because of their greater amount of Cys residues, they present a higher theoretical metal binding capacity than standard MTs. The calculation of this theoretical metal binding capacity takes into consideration that all Cys residues in vertebrate MTs are involved in heavy metal binding; therefore, the stoichiometry is $\mathrm{Cd}_{7}(\mathrm{Cys})_{20}$ for CdMTs and $\mathrm{Cu}_{12}(\mathrm{Cys})_{20}$ for CuMTs [4]. The 3D structure analysis of several MTs corroborates this stoichiometry [38]. We can assume that this stoichiometry is also applicable to Tetrahymena MTs and have calculated the theoretical binding capacity for all of them (Additional file 1). The shortest Tetrahymena CdMTs (TtheMTT5 and TmalaMTT4) (Table 2) are able to bind 8 or $9 \mathrm{Cd}^{2+} /$ molecule and up to $19 \mathrm{Cd}^{2+} /$ molecule (Additional file 1) in the case of TpyrMT-2, which is one of the longest CdMT (181 aa) with the highest amount of Cys residues (54 residues) (Table 2). The average amount of the theoretical $\mathrm{Cd}$ binding capacity of these CdMTs is about $15 \mathrm{Cd}^{2+} /$ molecule (Additional file 1), which is more than double that of standard MTs $\left(7 \mathrm{Cd}^{2+} /\right.$ molecule). Some of these data have been corroborated experimentally; for instance: $12 \mathrm{Cd}^{2+}$ per mole of protein or $11 \mathrm{Cd}^{2+}$ per polypeptide for TpyrMT-1 [39]. Likewise, a stable in vitro $\mathrm{Cd}_{16}(\mathrm{Cys})_{48}$ complex has been suggested [40] for TtheMTT1 (a similar value to the theoretical one assigned to this CdMT) (Additional file 1), and $\mathrm{Cd}_{11}(\mathrm{Cys})_{32}$ complex has also been suggested [40] for the CuMT TtheMTT2, with a metal-toCys residue ratio of about 1:3 for both $T$. thermophila MTs. In addition, it was found that $\mathrm{Cu}^{2+}$ cannot replace $\mathrm{Cd}^{2+}$ from the $\mathrm{Cd}_{16}$-TtheMTT1 complex, but $\mathrm{Cu}^{2+}$ can replace $\mathrm{Cd}^{2+}$ from the $\mathrm{Cd}_{11}$-TtheMTT2 complex [40]. This confirms the classification of the TtheMTT1 and TtheMTT2 as CdMT and CuMT, respectively. More recently, we have analysed the metal binding preference and abilities of the five MT isoforms from T. thermophila by electrospray mass spectrometry, circular dichroism and UV-vis spectrophotometry [25]. We conclude that both CdMT isoforms (TtheMTT1 and TtheMTT5) which yield unique $\mathrm{Cd}_{17^{-}}$and $\mathrm{Cd}_{8^{-}}$complexes, respectively, are optimal for $\mathrm{Cd}^{2+}$ coordination, thus corroborating the theoretical metal binding capacity values obtained for these CdMTs (Additional file 1). The MTT3 isoform showed poor binding abilities with both $\mathrm{Cd}^{2+}$ and $\mathrm{Cu}^{+}$, and yielded the best result whith $\mathrm{Zn}^{2+}$. Although this MT, also considered as a CdMT, has a theoretical metal binding capacity value of about 15, the two Histidine (His) residues present in the protein enhance the relative affinity for $\mathrm{Zn}^{2+}$ through their imidazol rings $[41,42]$ in comparison with $\mathrm{Cd}^{2+}$. His residues, the most frequent $\mathrm{Zn}$ ligands in metaloenzymes, are also present in MTs (1-4 residues/molecule) from a variety of species (bacteria, fungi, plants and animals), thus increasing the affinity for this essential metal. Of the Tetrahymena MTs, only two CdMTs (TtheMTT3 and TpatMTT2) (Fig. 3) contain His residues, while CuMTs contain nine isoforms with one or two His (Fig. 2), coinciding with the general knowledge that this amino acid is more abundant in CuMTs than in CdMTs. In addition, His residues have an important role in MT proteins as they stabilize the formation of metalprotein complexes [43]. Both T. thermophila CuMTs (TtheMTT2 and TtheMTT4 isoforms), were found to form homometallic $\mathrm{Cu}$-complexes (mainly $\mathrm{Cu}_{20}-\mathrm{MT}$ ) [25], which coincides with the theoretical metal binding capacity value obtained (19 Cu ions/molecule) (Additional file 1). Zn-MT complexes were only found in TtheMTT4 (mainly $\mathrm{Zn}_{10}$-MTT4) [25]. These CuMTs (TtheMTT2 and TtheMTT4) differ in only one relevant amino acid 
position $\left(\mathrm{Asn}^{89} / \mathrm{Lys}^{89}\right)$, and it is interesting how this amino acid position change increases the CuMT character (higher affinity for $\mathrm{Cu}$ ions) of TtheMTT2 (Asn) in relation to TtheMTT4 (Lys) [25]. This special feature has also been reported in snail MTs, balancing in favour of $\mathrm{Zn} /$ CdMTs (Lys) or CuMTs (Asn) [44].

Another peculiar characteristic of MTs (including those from Tetrahymena) is the large asymmetry in the ratio of specific amino acids, such as the positively charged amino acids Lys and Arg. There is a considerably higher use of Lys residues with respect to Arg residues, and this asymmetry (Lys > > Arg) appears in all reported MTs. In ciliate MTs the Arg residues are almost absent of the CdMTs, only two (TtheMTT3 and ThegMT2) present one Arg residue (Fig. 3), and only two CuMTs (TborMTT3 and ImMTT2) have Arg residues, with one and two residues, respectively (Fig. 2). The location of these Arg residues is the same as those of Lys residues in other ciliate MT sequences. These two positively charged amino acids (Lys and Arg) are mostly exposed to the protein surface and play important roles in protein stability by forming electrostatic interactions. Arginine forms a higher number of electrostatic interactions compared to lysine. Experiments carried out on the green fluorescent protein (GFP), after changing lysine for arginine on the protein surface and retaining protein activity, have shown that the GFP variant was relatively more stable compared to the control GFP (in the presence of urea, basic $\mathrm{pH}$ or ionic detergents), but the thermal stability of the protein was similar to the control [45]. On the other hand, proteins with elevated solubility, a higher expression and abundant intracellular levels have an increased ratio of Lys content to Arg content [46]. In general, MTs have large number of Lys residues and null or very few Arg residues per molecule, preferring higher solubility and the avoidance of protein aggregates to higher stability by forming a larger number of electrostatic interactions (salt-bridges or hydrogen bonds). This could therefore mean that the asymmetry (Lys > > Arg) reported in all MTs is a basic requirement for forming proteins with an elevated solubility and high intracellular level to respond to metal stress.

\section{Analysis of Tetrahymena MT cDNAs}

After comparing all new isolated cDNAs of putative MT genes with the genomic DNA from the corresponding Tetrahymena species, we confirmed that none of these genes have introns in their open reading frames, which is also the case in all previously reported Tetrahymena MT genes [13]. The absence of introns could be related to a faster gene response to different environmental stressors. The presence of introns can delay regulatory responses and they are selected against in genes with transcripts requiring rapid adjustment in order to survive environmental changes [47].
In general, the gene expression of Tetrahymena MT genes is very fast, as reported in a CdMT gene (MT-1) from $T$. pigmentosa, in which an approximately tenfold increase of this transcript was detected after $30 \mathrm{~min} \mathrm{Cd}$ treatment [15]. An exception was reported in the gene isoform MTT5 of T. thermophila, in which an intron was located in the 3'UTR of the corresponding cDNA. The existence of MTT5 mRNAs with and without this intron supports the first case of alternative intron splicing reported in this ciliate [19]. In the Tetrahymena Comparative Database (Broad Institute, Cambridge, USA) the MTT3 DNA sequence from $T$. malaccensis (registered as EIA_07390.2 hypothetical protein) shows a putative intron (60 nucleotides). After a more detailed analysis, we detected that the putative intron corresponds to the amino acid sequence of the second type 1 submodule from the second module, sequence that is quite conserved in almost all Tetrahymena CdMTs. The nucleotide sequence identified as an intron (EIA_07390.2) starts in GT and ends in AG (with a $68.3 \% \mathrm{~A}+\mathrm{T}$ ), and therefore, it might be assumed that it would coincide with the ciliate consensus intron ends (5'GTAAG/TAG 3'). A similar situation in which no introns are observed is detected in TamerMTT1 [KU052681] and TpatMTT1 [KU167652] cDNAs. The GT pair corresponds to a Cys residue (tgt codon), while AG pair corresponds to Glu (E) residue (gag codon). The same occurs in the TamerMTT1 and TpatMTT1 CdMT sequences, but not in the rest of the Tetrahymena CdMTs, because the majority codon used for Glu residues is gaa. In addition, the A + T content of these regions has very similar values to the complete ORF sequences from all CdMTs reported to date (an average of $60.5 \%$ ). All of this corroborates that the putative intron reported in a CdMT from T. malaccensis (EIA_07390.2) is not a real intron but rather an error.

In general, MT genes are mainly regulated at transcriptional level [48]. As in a previous study using an in silico analysis [19], we identified several conserved motifs in both 5' and 3'UTR regions from the new isolated cDNA molecules, which may be related to the regulation of their gene expression and/or transcript processing. In the 5'UTR region or putative promoter we identified two types of motifs (Tables 4 and 5): a TATA box (TAATAA) with an average number of $\approx 3$ motifs/ cDNA in both $\mathrm{Cd}$ - and CuMTs, and motifs similar to MTCM1 [19] with an average number of $\approx 5$ motifs/ cDNA in CdMTs or $\approx 3$ in CuMTs. This MTCM1 motif was identified in almost all Tetrahymena MT promoters (Tables 4 and 5), so these sequences might play an important role in the gene expression regulation of these MTs. Most MTCM1 motifs include the consensus sequence TGA(N)TCA or similar (where " $\mathrm{N}$ " means any nucleotide), which recalls to the sequence (TGA(G/ C)TCA) binding the eukaryotic AP-1 transcription factors [49]. In Saccharomyces cerevisiae an AP-1 
Table 4 Conserved motifs detected in 3' and 5' UTR regions of Tetrahymena CdMT genes

\begin{tabular}{|c|c|c|c|c|c|}
\hline \multirow[t]{3}{*}{ CdMT genes } & \multicolumn{2}{|r|}{ 5'UTR } & \multicolumn{3}{|c|}{$\begin{array}{r}\text { 3'UTR } \\
\end{array}$} \\
\hline & \multirow{2}{*}{$\begin{array}{l}\text { TATA box } \\
\text { (TAATAA) }\end{array}$} & \multirow{2}{*}{$\begin{array}{c}\text { MTCM1 motif copies (canonical } \\
\text { orientation) }\end{array}$} & \multicolumn{2}{|c|}{ Polyadenylation signals } & \multirow{2}{*}{$\begin{array}{c}\text { Degradation } \\
\text { signal } \\
\text { (ATTTA) }\end{array}$} \\
\hline & & & ATTAAA & AATAAA & \\
\hline TelliMTT1 ${ }^{a}$ & 6 & $\begin{array}{l}\text { GTTTGATTTCAATCAAT } \\
\text { TATTCAGTCATGGGT } \\
\text { CTGTGACTCATGAAT } \\
\text { TTGTGACTCTTGATT }\end{array}$ & 2 & 1 & 1 \\
\hline TelliMTT2 $2^{a}$ & 3 & $\begin{array}{l}\text { TGTTGAATCAGGCAA } \\
\text { ATCAAACTCATGAAT } \\
\text { TTGTGACTCTTGGTT }\end{array}$ & 2 & 1 & 2 \\
\hline TmalaMTT1 $1^{a}$ & 6 & $\begin{array}{l}\text { CTGTGATTCATGAAT } \\
\text { TCATGAATCATTATT } \\
\text { GATTGACTCATGATT } \\
\text { AAGTGAATCATGATT }\end{array}$ & 2 & 1 & 0 \\
\hline TmalaMTT2 $^{a}$ & 10 & $\begin{array}{l}\text { AACTAACTCATGATT } \\
\text { GCAAGACTCATGATG }\end{array}$ & 1 & 0 & 1 \\
\hline TmalaMTT3 $^{a}$ & 0 & ? & 2 & 3 & 1 \\
\hline TmalaMTT $^{a}$ & 0 & $?$ & 2 & 1 & 3 \\
\hline TpatMTT1 $1^{a}$ & 2 & $?$ & 0 & 0 & 2 \\
\hline TpatMTT2 $2^{a}$ & 2 & $?$ & 0 & 1 & 4 \\
\hline TborMTT1 ${ }^{a}$ & 3 & $\begin{array}{l}\text { ATCTGATTAATGATT } \\
\text { CAGTGATTCATAAGC } \\
\text { AAGTGATTCATGAAG } \\
\text { AGGTTGATCATGAAC }\end{array}$ & 0 & 0 & 1 \\
\hline TborMTT2 $^{a}$ & 2 & $\begin{array}{l}\text { TATTGATTCATTCTA } \\
\text { TATTGAATCATACTT } \\
\text { TTTTTGAATCAACATAA } \\
\text { GATTGACTCATTCAAA } \\
\text { TAGTGATTCATTAATT } \\
\text { AAATCAATCAATCAA }\end{array}$ & 0 & 2 & 1 \\
\hline TamerMTT1 ${ }^{a}$ & 2 & ? & 2 & 1 & 1 \\
\hline TamerMTT2 $^{a}$ & $?$ & $?$ & 2 & 0 & 1 \\
\hline TtheMTT1 & 2 & $\begin{array}{l}\text { ATGTGAATCATTAAT } \\
\text { TTGTGATTCTTGAAT } \\
\text { GATTGACTCATGATT }(2)^{b} \\
\text { ATGTGATTCTTGAAT } \\
\text { ACGTGATTCACGATT }\end{array}$ & 2 & 1 & 1 \\
\hline TtheMTT3 & 2 & $\begin{array}{l}\text { ATGTGATTCTTGAAT } \\
\text { GACTAAATCAAGAGT }\end{array}$ & 0 & 0 & 1 \\
\hline TtheMTT5 & 1 & $\begin{array}{l}\text { GTGTGATTCTTGAAT } \\
\text { ATGTGATTCATGAGT }(2)^{b} \\
\text { ATGTGAATCATGAGT } \\
\text { GTGTGAATCATGAGT }(4)^{b} \\
\text { GAGTGAATCATGAGT }(2)^{b} \\
\text { GTGTGAATCATGAGG }(2)^{b} \\
\text { TAGTCACTCATGAAT }\end{array}$ & 0 & 2 & 4 \\
\hline TpyrMT-1 & 4 & $\begin{array}{l}\text { ATGTGATTCTTGAGC } \\
\text { AAGTGATTCTTGAGC } \\
\text { TAGTGATTCCTGAAT } \\
\text { AAGTGATTCCTGAGT } \\
\text { AAGTGATTCTTGGAT }\end{array}$ & 1 & 1 & 4 \\
\hline
\end{tabular}

${ }^{a}$ New CdMT genes reported in this study. ${ }^{b}$ Numbers in parenthesis indicate the copy number/motif. TCA and TGA trinucleotides are highlighted in blue and yellow to facilitate motif sequence comparisons and identifications of the AP-1 binding related element (TGANTCA). ? : unknown 
Table 5 Conserved motifs described in $3^{\prime}$ and 5'UTR regions of Tetrahymena CuMT genes

\begin{tabular}{|c|c|c|c|c|c|}
\hline \multirow{3}{*}{ CuMT genes } & \multicolumn{2}{|r|}{ 5'UTR } & \multicolumn{3}{|c|}{ 3'UTR } \\
\hline & \multirow[t]{2}{*}{$\begin{array}{l}\text { TATA box } \\
\text { (TAATAA) }\end{array}$} & \multirow[t]{2}{*}{$\begin{array}{l}\text { MTCM1 motif copies } \\
\text { (canonical orientation) }\end{array}$} & \multicolumn{2}{|c|}{$\begin{array}{c}\text { Polyadenylation } \\
\text { signals }\end{array}$} & \multirow{2}{*}{$\begin{array}{c}\text { Degradation } \\
\text { signal } \\
\text { (ATTTA) }\end{array}$} \\
\hline & & & ATTAAA & AATAA & \\
\hline TelliMTT6 $^{a}$ & 6 & GAGTGATTCTTGAGG & 0 & 2 & 2 \\
\hline TelliMTT $8^{a}$ & 8 & $\begin{array}{l}\text { AACGAACTCATGAAT } \\
\text { AGAAAACTCATGAGT }\end{array}$ & 1 & 2 & 1 \\
\hline TmalaMTT5 $^{a}$ & 4 & $\begin{array}{l}\text { GTCTTCAATCATTCATT } \\
\text { ATATGAATTTATCATT }\end{array}$ & 0 & 1 & 2 \\
\hline TborMTT3 $^{a}$ & 2 & $\begin{array}{l}\text { TATATTATCATGACC } \\
\text { GTGATCTCAATCAAA }\end{array}$ & 3 & 2 & 2 \\
\hline TborMTT4 $^{a}$ & 2 & $\begin{array}{l}\text { CAAAAACTCATGAGC } \\
\text { AGATCAATCATTAAC } \\
\text { GTTTGATTCAGATAC } \\
\text { AATTCAATCATTACA }\end{array}$ & 2 & 2 & 2 \\
\hline TborMTT6 $^{a}$ & 6 & $\begin{array}{l}\text { ATTTGCATCATGATC } \\
\text { AATCATTCACTCA } \\
\text { CTTTCAATCAGCATA } \\
\text { TATATTATCATGACC } \\
\text { GTGATCTCAATCA }\end{array}$ & 1 & 3 & 0 \\
\hline TborMTT7 $^{a}$ & 1 & $\begin{array}{l}\text { TTATGATTTATGATA } \\
\text { CTAAGACTCATGACT }\end{array}$ & 4 & 1 & 1 \\
\hline TborMTT $^{a}$ & 1 & $\begin{array}{l}\text { AATTCAATCATTACA } \\
\text { CTATGAGTGATATTC } \\
\text { GAGTGAATCTTGAGG } \\
\text { AAATGATTCAAGATAA } \\
\text { TGAGGCTCATGAT }\end{array}$ & 2 & 2 & 2 \\
\hline TamerMTT3 ${ }^{a}$ & 0 & $?$ & 0 & 2 & 2 \\
\hline TtheMTT2 & 1 & $\begin{array}{l}\text { AATTCATATATGATA } \\
\text { GAGTGATTCCTGAGG }\end{array}$ & $?$ & $?$ & $?$ \\
\hline TtheMTT4 & 3 & $\begin{array}{l}\text { ATTTGATAATTGAAT } \\
\text { CTATGATTCAAGAGT }\end{array}$ & $?$ & $?$ & $?$ \\
\hline
\end{tabular}

${ }^{a}$ New CuMT genes described in this paper. TCA and TGA trinucleotides are highlighted in blue and yellow to facilitate motif sequence comparisons and identifications of the AP-1 binding related element (TGANTCA). ? : unknown

transcription factor (YAP-1) is involved in response to oxidative stress and metal resistance [50]. Transcription factors similar to AP-1 have been detected in the MT promoters of insects (Drosophila melanogaster) and mollusks (Crassostrea virginica) [51]. AP-1, also known as c-jun, is a member of the bZIP superfamily of eukaryotic DNA-binding transcription factors. In T. thermophila the number of MTCM1 motifs in the three CdMT putative promoters is correlated with the gene expression level of each gene therefore, the relative induction ranking of gene expression is: TtheMTT5>> TtheMTT1>TtheMTT3 [19]. This motif is present 6 times in TtheMTT1, twice in TtheMTT3 and 13 times in TtheMTT5 promoter region (Table 4). The promoter of the TtheMTT5 gene has a 416 bp tandem duplication (with $96 \%$ identity to each other). Five copies of the MTCM1 motif are present in each duplication and another three copies are near to the start codon [19].
Quantitative gene expression analysis revealed that TtheMTT5 is the gene most strongly induced by diverse environmental stressors (TtheMTT5 > > TtheMTT1 > TtheMTT3) [19]. The presence of the duplicated promoter region in TtheMTT5 may be related to the high expression level of this CdMT gene when compared with the rest of T. thermophila CdMT genes. There is no direct and clear correlation between the number of MTCM1 motifs in the putative promoter regions of each Tetrahymena MT gene studied and their higher or lower expression level.

Two types of polyadenylation signals were detected on 3'UTR regions of these cDNAs (Tables 4 and 5). The average number of these polyA sites is about 3.2 for CdMTs, and 3.9 for CuMTs. Likewise, mRNA degradation signals (ATTTA) appear in almost all MT genes analyzed, with an average number of 1.7 (Tables 4 and 5). 


\section{Comparative analysis of the MT gene expression under several environmental stressors}

Of the 21 new Tetrahymena MT genes only 6 were analyzed, using qRT-pCR, owing to the great similarity among MT gene nucleotide sequences isolated from the same Tetrahymena species, which makes it impossible to design specific primers to differentiate each gene. We studied the expression of two CdMT genes (TborMTT1 and TborMTT2) and one CuMT gene (TborMTT7) from $T$. borealis. The rest of the MT genes isolated from this species have a great similarity; the TborMTT3/TborMTT6 and TborMTT4/TborMTT8 pairs have 96 and $98 \%$ identity, respectively. One CuMT gene (TelliMTT6) from T. elliotti was analyzed because the TelliMTT1/TelliMTT2 pair has $85 \%$ identity, and although TelliMTT8 is very similar to TelliMTT6 the later is much longer, making it possible to design specific primers to amplify a fragment of the TelliMTT6 3' region. Only one CuMT gene(TamerMTT3) was analyzed from $T$. americanis because TamerMTT1 and TamerMTT3 are almost identical (99\%). Finally, one other CuMT gene expression (TmalaMTT5) was carried out from $T$. malaccensis because the TmalaMTT1/TmalaMTT2 and TmalaMTT3/TmalaMTT4 pairs have 84 and $94 \%$ identity, respectively. Chang et al. (2014), used qRTPCR to analyze the expression of a gene (TmalMT1) isolated from T. malaccensis under metal stress $\left(\mathrm{Cd}^{2+}, \mathrm{Zn}^{2+}\right.$, $\mathrm{Cu}^{2+}$ or $\mathrm{Pb}^{2+}$ ) [16], but this gene (which is the same as our
TmalaMTT1 gene) has $84 \%$ identity with a second CdMT gene, TmalaMTT2, which we isolated from the same Tetrahymena species, this being the reason we were not able to analyze them by qRT-PCR. Therefore, the gene expression analysis carried out by Chang et al. (2014) [16] very probably corresponds to the sum of both CdMT gene expressions $($ TmalMT1 $=$ TmalaMTT1 + TmalaMTT2). In the case of $T$. patula it was not possible to analyze the expression of any of the genes because both CdMT genes (TpatMTT1 and TpatMTT2) have $91 \%$ identity.

Figure 6 shows the relative fold induction values for each MT gene expression under five different metal(loid) stress treatments at $1 \mathrm{~h}$ (short exposure) or $24 \mathrm{~h}$ (long exposure). In general, the induction values are higher at $1 \mathrm{~h}$ of treatment than after $24 \mathrm{~h}$ of metal(loid) exposures, except for the CdMT gene TborMTT2 under $\mathrm{Cd}^{2+}, \mathrm{Cu}^{2+}$ or $\mathrm{Pb}^{2+}$ treatments (Fig. 6). Both putative CdMT genes from T. borealis (TborMTT1 and TborMTT2) are induced by $\mathrm{Cd}^{2+}$ among other inorganic cations, but there are several differences in the expression patterns of each gene isoform. At both 1 and $24 \mathrm{~h}$ exposures of $\mathrm{Cd}^{2+}, \mathrm{Pb}^{2+}$ or $\mathrm{As}^{5+}$, the expression levels for TborMTT1 are considerably higher than for the TborMTT2 gene. On the other hand, the TborMTT2 gene isoform seems to be induced later and more uniformly with these metal(loid)s. Therefore, under the same stress conditions, two differential gene expression behaviors are detected for these T. borealis CdMT isoforms;

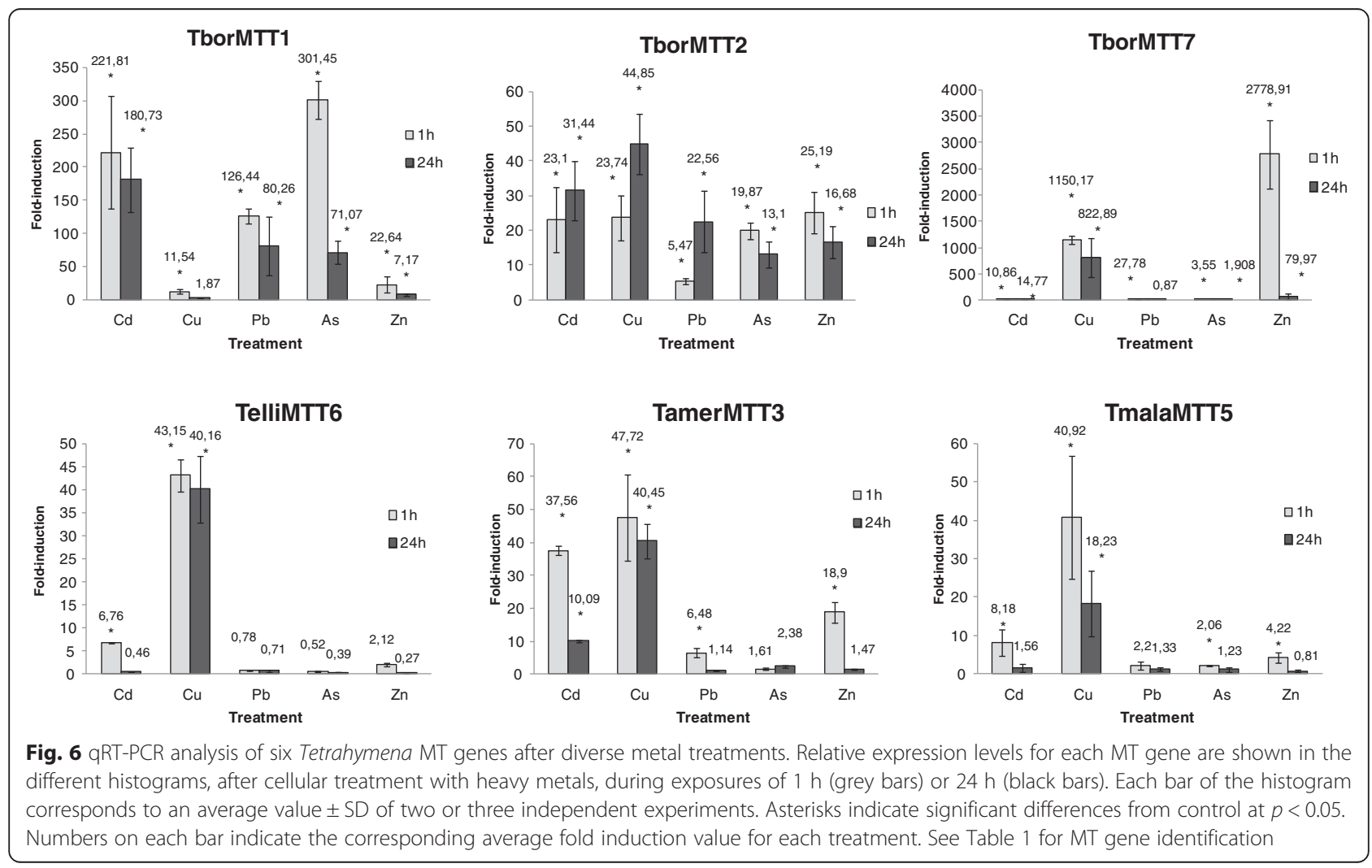


the TborMTT1 gene responds faster and with a higher level to most metal(loid) stress, while the TborMTT2 gene responds later and with a lower level under the same stress conditions (Fig. 6). Both genes respond to arsenate $\left(\mathrm{As}^{5+}\right)$. After $1 \mathrm{~h}$ of treatment with this toxic metalloid, TborMTT1 is induced about 300-fold while TborMTT2 is only induced $\approx 20$-fold. The toxicity of arsenic depends on its chemical form and state of oxidation, and is generally assigned to its capacity to produce ROS (reactive oxygen species). Arsenic-induced ROS originate lipid peroxidation and genotoxic damage [52]. Metallothioneins reduce arsenic toxicity, either because $\mathrm{As}^{5+}$ may interact with their thiol groups and to involve detoxification, or they may act as antioxidants to protect against the oxidative stress originated by $\mathrm{As}^{5+}$ [53]. In fact, arsenic induces MT gene expression [54], including some previously studied Tetrahymena MT genes (Table 6) [19, 23].

The rest of Tetrahymena MT genes analyzed are putative CuMTs, which are induced primarity but not exclusively by $\mathrm{Cu}^{2+}$ (Fig. 6), as is also the case in other

Table 6 Ranking of relative fold-induction values of Tetrahymena MT genes obtained by GRT-PCR analysis after different heavy metal treatments

\begin{tabular}{|c|c|c|c|c|}
\hline MT gene & Subfamily & Relative fold-induction value ranking & Treatment & Reference \\
\hline TpyrMT-1 & CdMT & $\mathrm{Cd}>\mathrm{Cu}>\mathrm{Zn}>\mathrm{Hg}$ & $1 \mathrm{~h}$ & {$[12]$} \\
\hline TpyrMT2 & CdMT & $\mathrm{Cd}>\mathrm{Cu}>\mathrm{Zn}>\mathrm{Hg}$ & $1 \mathrm{~h}$ & {$[12]$} \\
\hline \multirow[t]{3}{*}{ TtheMTT1 } & CdMT & $\mathrm{Cd}>\mathrm{Hg}>\mathrm{Cu}>\mathrm{Zn}$ & $30 \mathrm{~min}$ & [14] \\
\hline & & $\mathrm{Cd}>\mathrm{Zn}>\mathrm{Pb}>\mathrm{Cu}>\mathrm{Ni}$ & $1 \mathrm{~h}$ & [2] \\
\hline & & $\mathrm{Cd}>\mathrm{Pb}>\mathrm{As}>\mathrm{Cu}>\mathrm{Zn}>\mathrm{Ni}$ & $24 \mathrm{~h}$ & \\
\hline \multirow[t]{2}{*}{ TtheMTT3 } & CdMT & $\mathrm{Zn}>\mathrm{Cd}>\mathrm{Pb}>\mathrm{Ni}>\mathrm{Cu}$ & $1 \mathrm{~h}$ & [2] \\
\hline & & $\mathrm{Cd}>\mathrm{Zn}>\mathrm{As}>\mathrm{Ni}>\mathrm{Cu}>\mathrm{Pb}$ & $24 \mathrm{~h}$ & \\
\hline \multirow[t]{2}{*}{ TtheMTT5 } & CdMT & $\mathrm{Pb}>\mathrm{Cd}>\mathrm{Zn}>\mathrm{Cu}>\mathrm{Ni}$ & $1 \mathrm{~h}$ & [2] \\
\hline & & $\mathrm{Pb}>\mathrm{As}>\mathrm{Cd}>\mathrm{Cu}>\mathrm{Zn}>\mathrm{Ni}$ & $24 \mathrm{~h}$ & \\
\hline \multirow[t]{2}{*}{ TrosMTT1 } & CdMT & $\mathrm{Cd}>\mathrm{Pb}>\mathrm{As}>\mathrm{Cu}>\mathrm{Zn}$ & $1 \mathrm{~h}$ & [17] \\
\hline & & $\mathrm{Pb}>\mathrm{Cd}>\mathrm{As}>\mathrm{Zn}>\mathrm{Cu}>\mathrm{Ni}$ & $24 \mathrm{~h}$ & \\
\hline TpigMT-1 & CdMT & $\mathrm{Hg}>\mathrm{Pb}>\mathrm{Cd}>\mathrm{Cu}>\mathrm{Zn}$ & $1 \mathrm{~h}$ & [41] \\
\hline \multirow[t]{2}{*}{ ThegMT1 } & CdMT & $\mathrm{Zn}>\mathrm{Pb}>\mathrm{Cd}>\mathrm{Cu}$ & $1 \mathrm{~h}$ & [19] \\
\hline & & $\mathrm{Pb}>\mathrm{Cd}>\mathrm{Zn}>\mathrm{Cu}$ & $24 \mathrm{~h}$ & \\
\hline \multirow[t]{2}{*}{ ThegMT2 } & CdMT & $\mathrm{Zn}>\mathrm{Cd}>\mathrm{Cu}>\mathrm{Pb}$ & $1 \mathrm{~h}$ & [19] \\
\hline & & $\mathrm{Pb}>\mathrm{Zn}>\mathrm{Cd}>\mathrm{Cu}$ & $24 \mathrm{~h}$ & \\
\hline \multirow[t]{2}{*}{ TmalMT1 } & CdMT & $\mathrm{Cd}>\mathrm{Zn}>\mathrm{Cu}>\mathrm{Pb}$ & $1 \mathrm{~h}$ & [19] \\
\hline & & $\mathrm{Cd}>\mathrm{Zn}>\mathrm{Cu}>\mathrm{Pb}$ & $24 \mathrm{~h}$ & \\
\hline \multirow[t]{2}{*}{ TmobMT1 } & CdMT & $\mathrm{Cd}>\mathrm{Cu}>\mathrm{Pb}>\mathrm{Zn}$ & $1 \mathrm{~h}$ & [19] \\
\hline & & $\mathrm{Cd}>\mathrm{Pb}>\mathrm{Cu}>\mathrm{Zn}$ & $24 \mathrm{~h}$ & \\
\hline \multirow[t]{2}{*}{ TborMTT1 } & CdMT & $\mathrm{As}>\mathrm{Cd}>\mathrm{Pb}>\mathrm{Zn}>\mathrm{Cu}$ & $1 \mathrm{~h}$ & This paper \\
\hline & & $\mathrm{Cd}>\mathrm{Pb}>\mathrm{As}>\mathrm{Zn}>\mathrm{Cu}$ & $24 \mathrm{~h}$ & \\
\hline \multirow[t]{2}{*}{ TborMTT2 } & CdMT & $\mathrm{Zn}>\mathrm{Cd} \approx \mathrm{Cu}>\mathrm{As}>\mathrm{Pb}$ & $1 \mathrm{~h}$ & This paper \\
\hline & & $\mathrm{Cu}>\mathrm{Cd}>\mathrm{Pb}>\mathrm{Zn}>\mathrm{As}$ & $24 \mathrm{~h}$ & \\
\hline \multirow[t]{2}{*}{ TrosMTT2 } & CuMT & $\mathrm{Cu}>\mathrm{Pb}>\mathrm{Cd}>\mathrm{Zn}>\mathrm{As}$ & $1 \mathrm{~h}$ & {$[17]$} \\
\hline & & $\mathrm{Cu}>\mathrm{Zn}>\mathrm{Cd}>\mathrm{Pb}>\mathrm{Ni}$ & $24 \mathrm{~h}$ & \\
\hline \multirow[t]{2}{*}{ TborMTT7 } & CuMT & $\mathrm{Zn}>\mathrm{Cu}>>\mathrm{Pb}>\mathrm{Cd}>\mathrm{As}$ & $1 \mathrm{~h}$ & This paper \\
\hline & & $\mathrm{Cu}>\mathrm{Zn}>>\mathrm{Cd}>\mathrm{As}>\mathrm{Pb}$ & $24 \mathrm{~h}$ & \\
\hline \multirow[t]{2}{*}{ TelliMTT6 } & CuMT & $\mathrm{Cu}>\mathrm{Cd}>\mathrm{Zn}>\mathrm{Pb} \approx \mathrm{As}$ & $1 \mathrm{~h}$ & This paper \\
\hline & & $\mathrm{Cu}>>\mathrm{Pb}>\mathrm{Cd} \approx \mathrm{As} \approx \mathrm{Zn}$ & $24 \mathrm{~h}$ & \\
\hline \multirow[t]{2}{*}{ TamerMTT3 } & CuMT & $\mathrm{Cu}>\mathrm{Cd}>\mathrm{Zn}>\mathrm{Pb}>\mathrm{As}$ & $1 \mathrm{~h}$ & This paper \\
\hline & & $\mathrm{Cu}>\mathrm{Cd}>\mathrm{As}>\mathrm{Zn} \approx \mathrm{Pb}$ & $24 \mathrm{~h}$ & \\
\hline \multirow[t]{2}{*}{ TmalaMTT5 } & CuMT & $\mathrm{Cu}>\mathrm{Cd}>\mathrm{Zn}>\mathrm{Pb} \approx \mathrm{As}$ & $1 \mathrm{~h}$ & This paper \\
\hline & & $\mathrm{Cu}>\mathrm{Cd}>\mathrm{Pb} \approx \mathrm{As}>\mathrm{Zn}$ & $24 \mathrm{~h}$ & \\
\hline
\end{tabular}


previously studied CuMT genes from other Tetrahymena species [23] (Table 6). The TborMTT7 gene is enormously induced by $\mathrm{Zn}^{2+}$ and $\mathrm{Cu}^{2+}$, especially after $1 \mathrm{~h}$ of treatment. This is considerably more than other CuMT genes (Fig. 6), so this MT may play an important role in essential metal $\left(\mathrm{Zn}^{2+}\right.$ or $\left.\mathrm{Cu}^{2+}\right)$ homeostasis, which might also occur in CdMTs, such as; TtheMTT3 [19], ThegMT1, ThegMT2 [16] and other CuMTs (Table 6). Almost all of these have His residues in their molecules (Figs. 2 and 3), which, as previously indicated, enhance the relative affinity for $\mathrm{Zn}^{2+}[41,42]$ or $\mathrm{Cu}^{2+}$.

Comparisons of the qRT-PCR values obtained by different authors is difficult because of the different experimental conditions used, but even when conditions are the same and identical samples are used, it is difficult to reproduce experiments from different laboratories [55]. However, after the qRT-PCR values from different Tetrahymena MT genes are compared (Table 6), some general considerations can be inferred: a) In general, Tetrahymena CdMT genes are mainly induced by $\mathrm{Cd}^{2+}(\mathrm{Cd}>$ $\mathrm{Cu})$, whereas $\mathrm{CuMT}$ genes are induced by $\mathrm{Cu}^{2+}(\mathrm{Cu}>$ $\mathrm{Cd})$. This difference corroborates their separation in two previously well-defined sub-families (7a or CdMTs and 7b or CuMTs) [19]. b) Induction by $\mathrm{Zn}^{2+}$ sometimes occupies first position in the ranking of relative foldinduction values for both $\mathrm{Cd}$ - or CuMT genes but only with $1 \mathrm{~h}$ metal treatments, indicating a possible metal homeostatic role. c) Occasionally, induction by $\mathrm{Pb}^{2+}$ replaces $\mathrm{Cd}^{2+}$ at the top of the ranking, as in the case of TtheMTT5, TrosMTT1, ThegMT1 and ThegMT2. This is likely to be due to similarities between $\mathrm{Pb}^{2+}$ and $\mathrm{Cd}^{2+}$ in their chemical structure. MTs are induced by $\mathrm{Pb}^{2+}$ in rats, humans and fishes [56-58]. $\mathrm{Pb}^{2+}$ is second to $\mathrm{Cd}^{2+}$ in its ability to displace $\mathrm{Zn}^{2+}$ from hepatic $\mathrm{ZnMT}$ and is able to displace $\mathrm{Cd}^{2+}$ from the CdMT complex $[59,60]$. A transcriptome study in plants has revealed that many genes respond similarly to $\mathrm{Pb}^{2+}$ and $\mathrm{Cd}^{2+}$ [61]. Other metals can also induce Tetrahymena MT gene expression, for instance: $\mathrm{La}^{3+}$ induces the expression of both TtheMTT1 and TtheMTT2 genes. Fluorescence analysis shows that $\mathrm{La}^{3+}$ binds to both T. thermophila MTs [40], and that the TpigMT-1 gene is induced by $\mathrm{Hg}^{2+}$ [26].

MT gene expression, including both Tetrahymena Cdand CuMT genes, is induced by oxidative stress originated by $\mathrm{H}_{2} \mathrm{O}_{2}$ or organic compounds, such as Paraquat (PQ) or Menadione (MD) [19-21, 23, 26]. However, the foldinduction values obtained after PQ treatment are generally very low or null (Fig. 7). On the other hand, fold-induction values for MD ( $1 \mathrm{~h}$ treatment) are generally significantly higher than those obtained with PQ treatment (Fig. 7). Both compounds are pro-oxidants generating superoxide anions through redox cycling $[62,63]$, and they are known to potentially activate the transcription of some MTs [64], such as CUP1 from S. cerevisiae [65]. Certain antioxidant ability for both T. thermophila MTs (TtheMTT1 and TtheMTT2) has been suggested, because of the appearance of disulfide bonds in CdMT complexes after in vitro reaction with $\mathrm{NO}$ [40]. However, as shown by both previous results and our own (Fig. 7), other Tetrahymena CdMT genes (TpyrMT-2 and TrosMTT1) are not significantly induced by $\mathrm{H}_{2} \mathrm{O}_{2}$ or PQ [20, 23]. Likewise, the apoptosis inductor camptothecin (CAM) does not seem to be a good inducer of Tetrahymena MT gene expression, except in the case of the TborMTT7 gene, which is slightly induced ( $\approx 4.5$ - fold) after $24 \mathrm{~h}$ treatment (Fig. 7).

Other abiotic environmental stressors $(\mathrm{pH}$, temperature and starvation) have been analyzed as inducers of Tetrahymena MT gene expression. As shown in Fig. 8, acid pH induces gene expression in some Tetrahymena MT species (at both 3 or $24 \mathrm{~h}$ treatments), mainly in CuMTs. Under basic $\mathrm{pH}$ stress, only four new Tetrahymena genes are induced (at 3 or $24 \mathrm{~h}$ treatments) with fold-induction values between $\approx 4.7$ and 17.7. In general, $\mathrm{pH}$ changes induce a very wide and variable range of responses in Tetrahymena MT genes, from null [23] to a certain degree of induction irrespective of whether they are Cd- or CuMTs.

High temperature $\left(42{ }^{\circ} \mathrm{C}\right)$ induces gene expression in the majority of Tetrahymena MT isoforms (Fig. 8). T. rostrata MTs seem to be quite sensitive to thermal stress, because both isoforms (Cd- and $\mathrm{CuMT}$ ) are considerably induced by the $2 \mathrm{~h}$ heat-shock $\left(42{ }^{\circ} \mathrm{C}\right)$ treatment [23]. Likewise, the three isoform genes analyzed from $T$. borealis are also induced by $42{ }^{\circ} \mathrm{C}$ (24 h treatment) (Fig. 8). According to several phylogenetic studies, both Tetrahymena species are very closely related [66] (Fig. 4) and both species belong to the RSA2 riboset of the Borealis group, although $T$. rostrata is a histophagous ciliate, whereas and $T$. borealis not [66].

However, other MT genes from the Tetrahymena species are not induced by high temperature [19] (Fig. 8), although it has been reported that the TtheMTT1 gene is also induced (by about 8 -fold) at $40{ }^{\circ} \mathrm{C}$ ( $30 \mathrm{~min}$ exposure) [21]. In general, a low temperature $\left(4^{\circ} \mathrm{C}\right)$ does not induce the gene expression of Tetrahymena MT genes.

One of the main and more common environmental stressor to which cells are subject is starvation. Among newly analyzed Tetrahymena MT genes, the TborMTT1 gene has a higher fold-induction value, while the rest of the genes present very low or null induction values under starvation stress (Fig. 8). Previous studied of Tetrahymena MT genes have also shown induction (mainly after $24 \mathrm{~h}$ treatment) under starvation conditions $[19,23]$. The TtheMTT5 gene is expressed during ciliate conjugation (a sexual process induced and developed under starvation) [19], and the $S$. cerevisiae CUP1 metallothionein gene is induced under glucose starvation [67]. 

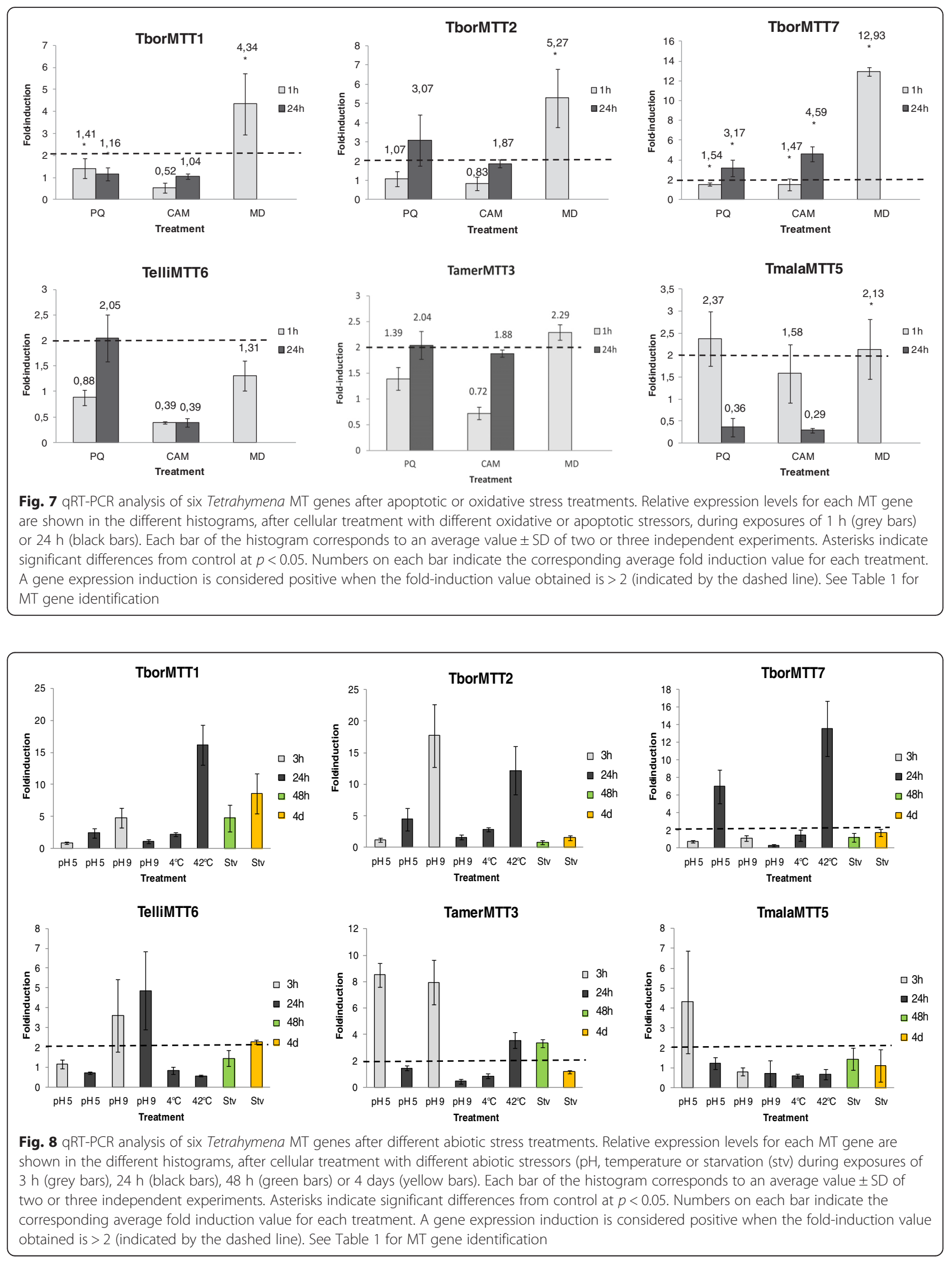
At present, this multi-stress character has been reported by the majority of expression analyses of MT genes under diverse abiotic stressors $[68,69]$. The transcriptional induction of several MT genes by a variety of stress conditions suggests that cellular exposure to one type of stressor might lead to the acquisition of tolerance towards another different stressor. This cross-protection reported in some organisms suggests at least the partial existence of overlapping between genome responses to different types of stress [70]. This overlapping genome expression comprises general stress-responsive genes, such as heat-shock or MT genes.

Independent of this general multi-stress feature of MTs, a differential gene expression level exists under the same environmental stressor, in different MT gene isoforms from the same subfamily, the same Tetrahymena species or among different species, which also seems to exist in different mammalian MT isoforms $[1,48]$. There are several examples in the same Tetrahymena species (Table 6): a) the three CdMT isoform genes from $T$. thermophila present differential expression patterns. Both TtheMTT1 and TtheMTT5 seem to be general stress and metal detoxification proteins. However, the gene expression induction values reached by TtheMTT5 gene are considerably higher than the rest of the $T$. thermophila MT isoforms [19], and it responds preferably but not exclusively to $\mathrm{Pb}^{2+}$. On the other hand, the TtheMTT1 gene preferably responds, at a lower level, to $\mathrm{Cd}^{2+}$ [19]. In fact, according to a physicochemical analysis of these MTs recombinantly synthesized as metal-complexes [25], TtheMTT1 has a higher affinity or binding preference by $\mathrm{Cd}^{2+}$ than TtheMTT5 isoform. The transformed $T$. thermophila strain (GFPMTT5) with the $P_{M T T 1}:: G F P:: M T T 5$ plasmid construct (which includes the TtheMTT1 promoter, the green fluorescent protein as a reporter gene, and the TtheMTT5 open reading frame) has been shown to be about 10 times more resistant to $\mathrm{Cd}^{2+}$ with regard to the wild-type strain [71], indicating that the TtheMTT1 promoter responds to $\mathrm{Cd}^{2+}$ and that an increase in the TtheMTT5 gene dose (into a cytoplasm multi-copy plasmid) affects the $\mathrm{Cd}^{2+} \mathrm{LC}_{50}$ value of this ciliate. A third Hiscontaining CdMT isoform (TtheMTT3) has a higher affinity to $\mathrm{Zn}^{2+}$ [19], and could be involved in the intracellular homeostasis of this metal; b) two CdMT isoform genes from T. hegewischi (ThegMT1 and ThegMT2) [16] show different gene expression induction patterns, although, as in other cases, these fold-induction values change depending on the metal time exposure (Table 6); c) likewise, the two new CdMT gene isoforms from $T$. borealis (TborMTT1 and TborMTT2) also have different gene expression induction patterns (Table 6).

In the majority of organisms, several isoforms of MT genes are present, suggesting the existence of differential cellular roles for them. The differential gene expression patterns reported from different MT isoforms under the same environmental stressor corroborate this idea. However, more extensive analysis needs to be done on the molecular behavior of each MT isoform and its relevance with respect to cellular response to a specific stress. Future analyses of knockout strains in one MT gene isoform and expression studies carried out on the rest will be of great importance for understanding the role of each MT isoform.

\section{Conclusions}

At present, a total of $42 \mathrm{MT}$ gene isoforms from different Tetrahymena species have been reported, of which 21 have been isolated as new cDNAs and reported in this study. In addition, one more MT gene from the sequenced macronuclear genome of the Tetrahymenarelated ciliate Ichthyophthirius multifiliis has been added to the ciliate MT analysis described in this paper. From analysis of the results, the following points can be conclude:

1. Two main Tetrahymena MT subfamilies (7a or CdMTs and $7 \mathrm{~b}$ or CuMTs) were once more corroborated after the 21 new MT cDNAs isolated from different Tetrahymena species were analyzed. Both MT subfamilies are based on their protein structural organization (Cys residue patterns) and their preferential gene induction under $\mathrm{Cd}^{2+}$ or $\mathrm{Cu}^{2+}$ stress.

2. Among all the known MTs from most organisms, the Tetrahymena MTs have several unique features. For example, they are considerably longer in size ( $\approx 67-74 \%$ for CdMTs and $\approx 24-57 \%$ for CuMTs), and therefore have higher molecular masses than standard MTs. CdMTs have relatively abundant CCC motifs with a strictly conserved modularsubmodular structure and higher metal binding capacities.

3. Among the Tetrahymena CdMTs, the tri-modular structure seems to occur mainly in the Borealis group, while the bi-modular structure is found in the majority of species from the Australis group.

4. The remarkable asymmetry between Tetrahymena $\mathrm{Cd}-$ and CuMTs in codon usage for glutamine residues, corroborates the possibility that CuMTs could have diverged earlier than CdMTs in the Tetrahymena genus.

5. The gene expression patterns from the new Tetrahymena MT isoforms analyzed corroborate their multi-stress character. Likewise, a differential gene expression behavior among different MT isoforms is present in the same Tetrahymena species. 


\section{Methods}

\section{Tetrahymena species, culture conditions and stress} treatments

The following five Tetrahymena species were used: T. borealis (SD 01609), T. elliotti 4EA (SD 01607), T. americanis (80C03), T. patula LFF (ATCC 50064), all supplied by ATCC (American Type Culture Collection) and T. malaccensis 436, supplied by the National Tetrahymena Stock Center (Cornell University). Cells were axenically grown in PP210 medium: $2 \% \mathrm{v} / \mathrm{v}$ proteose peptone aqueous solution (Pronadisa) supplemented with $100 \mu \mathrm{M} \mathrm{FeCl}$ (Panreac), $200 \mu \mathrm{g} / \mathrm{ml}$ of streptomycin sulfate (Calbiochem) and $200 \mu \mathrm{g} / \mathrm{ml}$ of penicillin G (Sigma), maintained at a constant temperature $\left(30 \pm 1^{\circ} \mathrm{C}\right)$.

Before RNA isolation, cell cultures were exposed to different stress conditions. Heavy-metal treatments were carried out for 1 or $24 \mathrm{~h}$ : $44.5 \mu \mathrm{M} \mathrm{Cd}{ }^{2+}\left(\mathrm{CdCl}_{2}\right)$ (except for $T$. borealis, which was treated with $\left.10 \mu \mathrm{M} \mathrm{Cd}^{2+}\right)$, $315 \mu \mathrm{M} \mathrm{Cu}^{2+}\left(\mathrm{CuSO}_{4} \cdot 5 \mathrm{H}_{2} \mathrm{O}\right), 965 \mu \mathrm{M} \mathrm{Pb}^{2+}\left(\mathrm{Pb}\left(\mathrm{NO}_{3}\right)_{2}\right)$, $100 \mu \mathrm{M} \mathrm{As}^{5+}\left(\mathrm{Na}_{2} \mathrm{HAsO}_{4}\right)$ and $38.2 \mathrm{mM} \mathrm{Zn}^{2+}\left(\mathrm{ZnSO}_{4} \cdot 7\right.$ $\mathrm{H}_{2} \mathrm{O}$ ) (Sigma). Metal concentrations were approximately half the $\mathrm{LC}_{50}$ values calculated in Tetrahymena thermophila [72], resulting in insignificant cell mortality for each species used in this study, as it was checked by flowcytometry (Additional file 2). Oxidative stress was induced by cell exposure ( 1 or $24 \mathrm{~h}$ ) to $7.7 \mathrm{mM}$ Paraquat (PQ) (Sigma) or $1 \mathrm{~h}$ to $2 \mathrm{mM}$ Menadione (MD) (Sigma). As an apoptosis inducer, $100 \mu \mathrm{M}$ Camptothecin (CAM) (Calbiochem) was used at 1 or $24 \mathrm{~h}$ exposures. Temperature stress was carried out by maintaining cells for $24 \mathrm{~h}$ in a cold $\left(4{ }^{\circ} \mathrm{C}\right)$ or hot $\left(42{ }^{\circ} \mathrm{C}\right)$ environment. $\mathrm{pH}$ stress was applied for 3 or $24 \mathrm{~h}$ under basic $(\mathrm{pH}$ 9) or acid ( $\mathrm{pH} 5)$ conditions. All these treatments were carried out in PP210 growth medium. Finally, starvation conditions were induced using a buffer $(0.01 \mathrm{mM}$ TrisHCl $\mathrm{pH}$ 6.8) for $48 \mathrm{~h}$ or 4 days. Ultrapure reagent grade $\mathrm{H}_{2} \mathrm{O}$ was used in all experiments, with maximum conductivity of $18.2 \mathrm{MV}$ obtained using a MILLI-Q water purification system (Millipore).

\section{Total DNA and RNA isolations and CDNA synthesis}

Exponential cell cultures $\left(1-3 \times 10^{5}\right.$ cells $\left./ \mathrm{ml}\right)$ of the different Tetrahymena species were harvested by centrifugation at $2800 \mathrm{rpm}$ for $3 \mathrm{~min}$. Total DNA was isolated using the protocol described in [73] and samples were treated with $10 \mathrm{mg} / \mathrm{ml}$ RNase A (Thermo- Scientific) for $2 \mathrm{~h}$ at $37^{\circ} \mathrm{C}$. Total RNA samples were isolated from previously stressed exponential cell cultures using the TRIzol Reagent method (Invitrogen). RNA samples were treated with DNase I (Roche) for $30 \mathrm{~min}$ at $37^{\circ} \mathrm{C}$. DNA and RNA integrity was tested by agarose gel electrophoresis. MultiScribe Reverse Transcriptase 50 units/ $\mu$ l (Life Technologies) and oligo(dT)-adaptor primer (Roche) were used to synthesize the cDNAs from $3.5 \mu \mathrm{g}$ of the total RNA samples.

\section{Standard PCR reactions, 5'/3' RACE and cloning}

Convergent degenerate primers (MET1/MET2 and MTCU1/MTCU2) were designed, using the amino acid sequence of the CdMT TpyrMT-1 [14] and the nucleotide sequence of the CuMT TtherMTT2 [19] in order to amplify putative CdMTs or CuMTs from different Tetrahymena species (Additional file 3). Standard PCR was carried out using the AmpliTaq Gold PCR Master Mix and $1.25 \mathrm{U} /$ reaction of the AmpliTaq Gold DNA Polymerase (Applied Biosystems). The following PCR program was applied: $7 \mathrm{~min}$ at $94^{\circ} \mathrm{C}, 30$ cycles of $1 \mathrm{~min}$ at $94{ }^{\circ} \mathrm{C}, 1 \mathrm{~min}$ at $50 \pm 3{ }^{\circ} \mathrm{C}$ and $2 \mathrm{~min}$ at $72{ }^{\circ} \mathrm{C}$ and finally, 5 min at $72{ }^{\circ} \mathrm{C}$. The full-length of cDNA sequences was obtained using 3' or 5' RACE kits: 3' RACE System for Rapid Amplification of cDNA Ends (Invitrogen) or 5' RACE System for Rapid Amplification of cDNA Ends (Invitrogen). In the 3' RACE system an adaptor primer (AP) and the AUAP primer supplied with the kit was generally used but in some cases we designed a specific primer for a specific sequence. AAP primer (Invitrogen) was used in the $5^{\prime}$ RACE, and we also designed a specific primer for each sequence (Additional file 3). PCR products were analyzed by standard $1.5 \%$ agarose gel electrophoresis in TAE $1 \mathrm{x}$ buffer (40 mM Tris, $1 \mathrm{~m}$ MEDTA and $5.7 \%$ glacial acetic acid) and stained with GelRed (Biotium) (3x in water). They were then cloned using the TOPO TA Cloning Kit (Invitrogen).

\section{Quantitative real-time RT-PCR}

cDNA samples were amplified in duplicate in 96 microtiter plates (Applied Biosystems). Each PCR reaction $(20 \mu \mathrm{l})$ contained: $10 \mu \mathrm{l}$ of SBYR Green (Takara), $1 \mu \mathrm{l}$ of each primer (at $300 \mathrm{nM}$ final concentration), $3 \mu \mathrm{l}$ of ultrapure sterile water and $5 \mu \mathrm{l}$ of cDNA. PCR primers (Additional file 3) were designed using the "Primer Quest and Probe Design" online-application of IDT (Integrated DNA Technologies). $\alpha$-tubulin and $\beta$-actin were used as the endogenous control or normalizer genes. Primer specificity was tested, melting curves were obtained and each PCR product was confirmed by gel electrophoresis and sequencing. Real-time RT-PCR reactions were carried out in an iQ5 real-time PCR apparatus (Bio-Rad). The thermal cycling protocol was as follows: 5 min at $95{ }^{\circ} \mathrm{C}, 40$ cycles $\left(30 \mathrm{~s}\right.$ at $95{ }^{\circ} \mathrm{C}, 30 \mathrm{~s}$ at $55^{\circ} \mathrm{C}$ and $20 \mathrm{~s}$ at $72{ }^{\circ} \mathrm{C}$ ), $1 \mathrm{~min}$ at $95^{\circ} \mathrm{C}$ and $1 \mathrm{~min}$ at $55^{\circ} \mathrm{C}$. All controls were negative (no template control or RT minus control). Amplification efficiency (E) was measured by using 10-fold serial dilutions of a positive control PCR template. The efficiency requirement was met for all the tested genes (Additional file 4). Results were finally processed by the standard-curve method (http://www6.appliedbiosystems.com/support/ tutorials/pdf/performing_rq_gene_exp_rtpcr.pdf). 


\section{DNA sequencing and in silico analysis of nucleotide and amino acid sequences}

DNA sequences were obtained with the ABI Prism 3730 DNA Analyser sequencer (Applied Biosystem). In order to look for new MT sequences we also analyzed the macronuclear genomes of $T$. malaccensis, $T$. borealis and T. elliotti with the BLAST program on the Tetrahymena Comparative Database website (http://www.broadinstitute.org/scientific-comunity/science/ programs/genome-sequencing-and-analysis/update-ourmicrobial-eukaryotes) and the macronuclear genome of $I$. multifiliis with the BLAST program on the Ichthyophthirius Genome Database website (http://ich.ciliate.org/index.php/ home/welcome). Multiple sequence alignments were performed using T-Coffee online application (which uses the Clustal Wallis method) (Tree-based Consistency Objective Function for Alignment Evaluation) [74]. The phylogenetic trees of both Tetrahymena MTs and SSrRNAs were built using the maximum likehood algorithm (MEGA 5.05, using the Poisson model). Phylogenetic trees (Newick) and alignments (FASTA) are available from TreeBase (http://purl.org/phylo/treebase/phylows/ study/TB2:S18773, http://purl.org/phylo/treebase/phylows/ study/TB2:S18776) with references: TB2:S18773 and TB2:S18776. Both, 5' and 3'UTR conserved motifs were searched, based on our previous research work [19].

\section{Nucleotide sequence accession numbers}

The 21 new cDNA sequences have been deposited in the GenBank Database. All GenBank accession numbers of MT genes referred on this article are shown in Additional file 5 .

\section{Availability of data and materials}

The datasets supporting the conclusions of this article are included within the article (and its Additional file 5) and are available in the TreeBase repository (http://purl.org/ phylo/treebase/phylows/study) with references: TB2:S18773 and TB2:S18776.

\section{Additional files}

Additional file 1: Theoretical metal binding capacity for Tetrahymena Cd- and CuMTs. (DOCX 16 kb)

Additional file 2: Heavy metal toxicity analysis. (DOCX $17 \mathrm{~kb}$ )

Additional file 3: Primers for standard PCR and qRT-PCR. (DOCX $16 \mathrm{~kb}$ )

Additional file 4: Quantitative RT-PCR standard-curve parameters. (DOCX $18 \mathrm{~kb}$ )

Additional file 5: Ciliate metallothionein GenBank accession numbers. (DOCX $17 \mathrm{~kb}$ )

\section{Abbreviations}

CdMTs: cadmium-binding MTs; CuMTs: copper-binding-MTs; LC 50 : lethal concentration killing $50 \%$ of cell population; MTs: metallothioneins;
ORF: open reading frame; qRT-PCR: quantitative reverse transcription polymerase chain reaction; SSrRNA: small subunit ribosomal RNA.

\section{Competing interests}

The authors declare that they have no competing interests.

\section{Authors' contributions}

$\mathrm{PdF}$ isolated and analysed most of the cDNAs and drew up the first draft of the manuscript. Other CDNAs were isolated by LMM. SD and AMG helped with the bioinformatic analysis. The project was conceived by JCG who provided overall supervision of the study and the drafting of the manuscript. All the authors read and approved the final manuscript.

\section{Acknowledgements}

This research work was supported by the Santander/Complutense PR6/1318856 grant to JCG. A PhD scholarship was awarded to PdF by the Spanish Ministry of Education (FPU12/02789)

\section{Author details}

${ }^{1}$ Departamento Microbiología-III, Facultad de Biología. C/José Antonio Novais, 12, Universidad Complutense de Madrid (UCM), 28040 Madrid, Spain. ¿Universidad Castilla-La Mancha, Campus Tecnológico de la fábrica de armas, Edificio Sabatini. Av. Carlos III, s/n. 45071 Toledo, Spain.

Received: 17 December 2015 Accepted: 22 April 2016

Published online: 10 May 2016

\section{References}

1. Coyle P, Philcox JC, Carey LC, Rofe AM. Metallothionein: the multipurpose protein. Cell Mol Life Sci. 2002;59:627-47.

2. Viarengo A, Burlando B, Ceratto N, Panfoli I. Antioxidant role of metallothioneins: a comparative overview. Cell Mol Biol. 2000;46:407-17.

3. Cousins RJ. Absorption, transport and hepatic metabolism of copper and Zn: special reference to metallothionein and caeruloplasmin. Physiol Rev. 1985:65:238-309.

4. Klaassen CD, Liu J, Choudhuri S. Metallothionein: an intracellular protein to protect against cadmium toxicity. Annu Rev Pharmacol Toxicol. 1999:39:267-94

5. Penkowa M, Carrasco J, Giralt M, Molinero A, Hernandez J, et al. Altered central nervous system cytokine-growth factor expression profiles and angiogenesis in metallothionein-I + II deficient mice. J Cereb Blood Flow Metab. 2000;20:1174-89.

6. Swindell WR. Metallothionein and the biology of aging. Ageing Res Rev. 2011;10:132-45.

7. Vidal F, Hidalgo J. Effect of zinc and copper on preimplantation mouse embryo development in vitro and metallothionein levels. Zygote. 1993;1:225-9.

8. Margoshes $\mathrm{M}$, Vallee BL. A cadmium protein from the equine kidney cortex. J Am Chem Soc. 1957;79:1813-4.

9. Capdevila M, Atrian S. Metallothionein protein evolution: a miniassay. J Biol Inorg Chem. 2011;16:977-89.

10. Guirola M, Pérez-Rafael S, Capdevila M, Palacios O, Atrian S. Metal dealing at the origin of the Chordata phylum: the metallothionein system and metal overload response in amphioxus. PLoS ONE. 2012;7(8):e43299.

11. Robinson NJ, Whitchall SK, Cavet JS. Microbial metallothioneins. In: Poole RK, editor. Advances in microbial physiology. New York: Academic; 2001. p. 183-213.

12. Gutiérrez JC, Amaro F, Martín-González A. From heavy metal-binders to biosensors: ciliate metallothioneins discussed. BioEssays. 2009;31:805-16.

13. Gutiérrez JC, Amaro F, Díaz S, De Francisco P, Cubas LL, Martín-González A. Ciliate metallothioneins: unique microbial eukaryotic heavy-metal-binder molecules. J Biol Inorg Chem. 2011:16:1025-34.

14. Piccinni E, Bertagia D, Santovito G, Miceli C, Kraen A. Cadmium metallothionein gene of Tetrahymena pyriformis. Gene. 1999;234:51-9.

15. Boldrin F, Santovito G, Irato P, Piccinni E. Metal interaction and regulation of Tetrahymena pigmentosa metallothionein genes. Protist. 2002;153:283-91.

16. Chang Y, Liu G, Guo L, Liu H, Yuan D, Xiong J, et al. Cd-Metallothionein in three additional Tetrahymena species: intragenic repeat patterns and induction by metal ions. J Eukaryot Microbiol. 2014:61:333-42.

17. Shuja RN, Shakoori AR. Identification and cloning of first cadmium metallothionein like gene from locally isolated ciliate, Paramecium sp. Mol Biol Rep. 2009;36:549-60

18. Binz PA, Kägi JHR. Metallothionein: Molecular evolution and classification. In: Klaasen C, editor. Metallothionein IV. Basel: Birkhäuser, Verlag; 1999. p. 7-13. 
19. Díaz S, Amaro F, Rico D, Campos V, Benítez L, Martín-González A, et al. Tetrahymena metallothioneins fall into two discrete subfamilies. PLoS ONE. 2007;2:e291

20. Fu C, Miao W. Cloning and characterization of a new multi-stress inducible metallothionein gene in Tetrahymena pyriformis. Protist. 2006; 157:193-203.

21. Dondero F, Cavaletto M, Chezzi AR, La Terza A, Banni M, Viarengo A Biochemical characterization and quantitative gene expression analysis of the multi-stress inducible metallothionein from Tetrahymena thermophila. Protist. 2004;155:157-68.

22. Shuja RN, Shakoori AR. Identification, cloning and sequencing of a novel stress inducible metallothionein gene from locally isolated Tetrahymena tropicalis lahorensis. Gene. 2007:405:19-26.

23. Amaro F, De Lucas MP, Martín-González A, Gutiérrez JC. Two new members of the Tetrahymena multi-stress inducible metallothionein family: Characterization and expression analysis of $T$. rostrata $\mathrm{Cd} / \mathrm{Cu}$ metallothionein genes. Gene. 2008;423:85-91.

24. Boldrin F, Santovito G, Formigari A, Bisharyan Y, Cassidy-Hanley D, Clark TG, et al. MTT2, a copper-inducible metallothionein gene from Tetrahymena thermophila. Comp Biochem Physiol C Toxicol Pharmacol. 2008;147:232-40.

25. Espart A, Marín M, Gil-Moreno S, Palacios O, Amaro F, Martín-González A, et al. Hints for metal-preference protein sequence determinants: different metal binding features of the five Tetrahymena thermophila metallothioneins. Int J Biol Sci. 2015;11(4):456-71.

26. Guo L, Fu C, Miao W. Cloning, characterization and gene expression analysis of a novel cadmium metallothionein gene in Tetrahymena pigmentosa. Gene. 2008:423:29-35.

27. Boldrin F, Santovito G, Negrisolo E, Piccinni E. Cloning and sequencing of four new metallothionein genes from Tetrahymena thermophila and T. pigmentosa. Evolutionary relationships in Tetrahymena MT family. Protist. 2003;154:431-42

28. Chantangsi C, Lynn DH. Phylogenetic relationships within the genus Tetrahymena inferred from the cytochrome c oxidase subunit 1 and small subunit ribosomal RNA genes. Mol Phylogenet Evol. 2008;49:979-87.

29. Henkel G, Krebs B. Metallothioneins: zinc, cadmium, mercury and copper thiolates and selenolates mimicking protein active site features-structura aspects and biological implications. Chem Rev. 2004;104:801-24.

30. Grüber C, Stürzenbaum S, Gehrig P, Sack R, Hunziker P, Berger B, et al. Isolation and characterization of a self-sufficient one-domain protein (Cd)-metallothionein from Eisenia foetida. Eur J Biochem. 2000;267:573-82.

31. Trinchella F, Riggio M, Filosa S, Parisi E, Scudiero R. Molecular cloning and sequencing of metallothionein in squamates: new insights into the evolution of the metallothionein genes in vertebrates. Gene. 2008;423:48-56.

32. Valls M, Bofill R, González-Duarte R, González-Duarte P, Capdevila M, Atrian S. A new insight into metallothionein (MT) classification and evolution: the in vivo and in vitro metal binding features of Homarus americanus recombinant MT. J Biol Chem. 2001;276:32835-43.

33. Bargelloni L, Scudiero R, Parisi E, Carginale V, Capasso C, Patarnello T. Metallothioneins in Antarctic fish: evidence for independent duplication and gene conversion. Mol Biol Evol. 1999;16:885-97.

34. Maroni G, Wise J, Young JE, Otto E. Metallothionein geneduplications and metal tolerance in natural populations of Drosophila melanogaster. Genetics. 1987;117:739-44.

35. Chiera NM, Rowinska-Zyrek M, Wieczorek R, Guerrini R, Witkowska D, Remelli $M$, et al. Unexpected impact of the number of glutamine residues on metal complex stability. Metallomics. 2013;5:214-21.

36. Baroin-Tourancheau A, Tsao N, Klobutcher LA, Pearlman RE, Adoutte A. Genetic code deviations in the ciliates: Evidence for multiple and independent events. EMBO J. 1995;14:3262-7.

37. Lozupone CA, Knight RD, Landweber LF. The molecular basis of nuclear genetic code change in ciliates. Curr Biol. 2001;11:65-74.

38. Peroza EA, Schmucki R, Güntert P, Preisinger E, Zerbe O. The $\beta E$-domain of wheat Ec-1 metallothionein: a metal-binding domain with a distinctive structure. J Mol Biol. 2009:387:207-18.

39. Domenech J, Bofill R, Tinti A, Torreggiani A, Atrian S, Capdevila M. Comparative insights into the $\mathrm{Zn}(\mathrm{II})$-, $\mathrm{Cd}(\mathrm{II})$ - and $\mathrm{Cu}(\mathrm{II})$-binding features on the protozoan Tetrahymena pyriformis MT1 metallothionein. Biochim Biophys Acta. 2008;1784:693-704.

40. Wang Q, Xu J, Chai B, Liang A, Wang W. Functional comparison of metallothioneins MTT1 and MTT2 from Tetrahymena thermophila. Arch Biochem Biophys. 2011;509:107-76.
41. Tucker SL, Thornton CR, Tasker K, Jacob C, Giles G, Edgan M, et al. A fungal metallothionein is required for patogenity of Magnaporthe grisea. Plant Cell. 2004; 16:1575-88.

42. Daniels MJ, Turner-Cavet JS, Selkirk R, Sun H, Parkinson JA, Sadler PJ, et al. Coordination of $\mathrm{Zn}^{2+}$ (and $\mathrm{Cd}^{2+}$ ) by prokaryotic metallothionein. Involvement of His-Imidazole. J Biol Chem. 1998;273:22957-61.

43. Blindauer CA. Metallothioneins with unusual residues: histidines as modulators of zinc affinity and reactivity. J Inorg Biochem. 2007;102:507-21.

44. Perez-Rafael S, Monteiro F, Dallinger R, Atrian S, Palacios O, Capdevila M. Cantareus aspersus metallothionein metal binding abilities: the unspecific $\mathrm{CaCd} / \mathrm{CuMT}$ isoform provides hints about the metal preference determinants in metallothioneins. BBA-Proteins Proteomics. 2014;1844:1694-707.

45. Sokalingam S, Raghunathan G, Soundrarajan N, Lee SG. A study on the effect of surface lysine to arginine mutagenesis on protein stability and structure using green fluorescent protein. PLoS ONE. 2012;7:e40410.

46. Warwicker J, Charonis S, Curtis RA. Lysine and arginine content of proteins: computational analysis suggests a new tool for solubility design. Mol Pharmaceutics. 2014;11:294-303.

47. Jeffares DC, Penkett CJ, Bahler J. Rapidly regulated genes are intron poor. Trends Genet. 2008;24:375-8.

48. Miles AT, Hawksworth GM, Beattie JH, Rodilla V. Induction, regulation, degradation and biological significance of mammalian metallothioneins. Crit Rev Biochem Mol Biol. 2000;35:35-70.

49. Shaulian E, Karin M. AP-1 as a regulator of cell life and death. Nat Cell Biol. 2002;4E:131-6.

50. Wu A, Wemmie JA, Edgington NP, Goebl M, Guevara JL, Moye-Rowley WS. Yeast bZIP proteins mediate pleotropic drug and metal resistance. J Biol Chem. 1993:268:18850-8.

51. Jenny MJ, Warr GW, Ringwood AR, Baltzegar DA, Chapman RW. Regulation of metallothionein genes in the American oyster (Crassostrea virginica): ontogeny and differential expression in response to different stressors. Gene. 2006;379:156-65.

52. Shi H, Shi X, Liu KJ. Oxidative mechanism of arsenic toxicity and carcinogenesis. Mol Cell Biochem. 2004;255:67-78.

53. Qu W, Waalkes MP. Metallothionein blocks oxidative DNA damage induced by acute inorganic arsenic exposure. Toxicol Appl Pharmacol. 2015;282(3):267-74

54. Ganger R, Garla R, Mohanty BP, Bansal MP and Garg ML. Protective effects of zinc against acute arsenic toxicity by regulating antioxidant defense system and cumulative metallothionein expression. Biol Trace Elem Res. 2015.

55. Bustin SA. Absolute quantification of mRNA using real-time reverse transcription polymerase chain reaction assays. J Mol Endocrinol. 2000;25:169-93.

56. Ikebuchi H, Teshima R, Suzuki T, Terao T, Yamane Y. Simultaneous induction of $\mathrm{Pb}$-metallothionein-like protein and $\mathrm{Zn}$-thionein in the liver of rats given lead acetate. Biochem J. 1986:233:541-6.

57. Church HJ, Day JP, Braithwaite RA, Brown SS. Binding the lead to a metallothionein-like protein in human erythrocytes. J Inorg Biochem. 1993;49:55-68.

58. Cheung A, Pok L, Vincent KLL, King MC. Tilapia metallothionein genes: PCRcloning and gene expression studies. Biochim Biophys Acta. 2005;1731:191-201.

59. Waalkes MP, Harvey MJ, Klaassen CD. Relative in vitro affinity of hepatic metallothionein for metals. Toxicol Lett. 1984;20:33-9.

60. Erk M, Raspor B. Interference of $\mathrm{Pb}$ leaching from the $\mathrm{pH}$ electrode on $\mathrm{Cd}$ metallothionein complex. Analitica Chimica Acta. 2001;442:165-70.

61. Kovalchuk I, Titov V, Hohn B, Kovalchuk O. Transcriptome profiling reveals similarities and differences in plant responses to cadmium and lead. Mutat Res. 2005;570:149-61.

62. Kappus $\mathrm{H}$, Sies $\mathrm{H}$. Toxic drug effects associated with oxygen metabolism: redox cycling and lipid peroxidation. Experientia. 1981;37:1233-41.

63. Thor H, Smith MT, Hartzell P, Bellomo G, Jewell SA, Orrenius S. The metabolism of menadione (2-methyl-1,4-naphthoquinone) by isolated hepatocytes. J Biol Chem. 1982;257:12419-25.

64. Bauman JW, Madhu C, McJim Jr JM, Liu Y, Klaassen CD. Induction of hepatic metallothionein by paraquat. Toxicol Appl Pharmacol. 1992;117:233-41.

65. Liu X, Thiele DJ. Oxidative stress induces heat shock factor phosphorylation and HSF-dependent activation of yeast metallothionein gene transcription. Genes Dev. 1996;10(5):592-603.

66. Strüder-Kypke MC, Wright ADG, Jerome CA, Lynn DH. Parallel evolution of histophagy in ciliates of the genus Tetrahymena. BMC Evol Biol. 2001;1:5.

67. Mager WH, Kruijft AJJ. Stress-induced transcriptional activation. Microbiol Rev. 1995;59:506-31. 
68. Yang M, Zhang F, Wang F, Dong Z, Cao Q, Chen M. Characterization of a type 1 metallothionein gene from the stresses-tolerant plant Ziziphus jujuba. Int J Mol Sci. 2015;16:16750-62.

69. Russo R, Bonaventura R, Matranga V. Time- and dose-dependent gene expression in sea urchin embryos exposed to UVB. Mar Environ Res. 2014;93:85-92.

70. Estruch F. Stress-controlled transcription factors, stress-induced genes and stress tolerance in budding yeast. FEMS Microbiol Rev. 2000;24:469-86.

71. Amaro F, Turkewitz AP, Martín-González A, Gutiérrez JC. Functional GFPmetallothionein from Tetrahymena thermophila: a potential whole-cell biosensor for monitoring heavy metal pollution and a cell model to study metallothionein overproduction effects. Biometals. 2014;27:195-205.

72. Gallego A, Martín-González A, Ortega R, Gutiérrez JC. Flow cytometry assessment of cytotoxicity and reactive oxygen species generation by single and binary mixtures of cadmium, zinc and copper on populations of the ciliated protozoan Tetrahymena thermophila. Chemosphere. 2007;68:647-61.

73. Martín-Platero AM, Valdivia E, Maqueda M, Martínez-Bueno M. Fast, convenient, and economical method for isolating genomic DNA from lactic acid bacteria using a modification of the protein "salting-out" procedure. Anal Biochem. 2007;366:102-4.

74. Notredame C, Higgins DG, Heringa J. T-Coffee: A novel method for fast and accurate multiple sequence alignment. J Mol Biol. 2000;302:205-17.

\section{Submit your next manuscript to BioMed Central} and we will help you at every step:

- We accept pre-submission inquiries

- Our selector tool helps you to find the most relevant journal

- We provide round the clock customer support

- Convenient online submission

- Thorough peer review

- Inclusion in PubMed and all major indexing services

- Maximum visibility for your research

Submit your manuscript at www.biomedcentral.com/submit

) Biomed Central 